\title{
La competencia municipal de autorización de los establecimientos donde se aplican técnicas de tatuaje y perforación cutánea (piercing)
}

\author{
Juan Francisco Pérez Gálvez \\ Profesor Titular de Derecho Administrativo \\ Universidad de Almería
}

SUMARIO: I. IDEAS GENERALES. II. DETERMINACIONES CONCEPTUALES. 1. Centro sanitario. 2. Técnica. 3. Establecimiento de tatuaje o piercing, áreas del mismo, técnicas aplicadas y personal que las desarrolla. III. NATURALEZA. IV. CLASIFICACIÓN. V. GRUPO NORMATIVO REGULADOR. 1. Estatal. 2. Autonómico. 3. Local. VI. CARACTERÍSTICAS DE LOS CENTROS Y ESTABLECIMIENTOS. 1. Condiciones generales de los locales. 2. Distribución funcional. 3. Equipo e instrumental. 4. Personal. 4.1. Requisitos relativos al personal aplicador de técnicas de tatuaje y perforación cutánea. 4.2. Formación. 4.2.1. Obligación de formación del personal. 4.2.2. Homologación de cursos de formación. 4.2.3. Requisitos de los cursos de formación. 5. Quejas y reclamaciones. VII. AUTORIZACIÓN. 1. Administrativa del centro. 2. Del usuario. 2.1. Información y respeto de las decisiones adoptadas libre y voluntariamente por el usuario: Una relación entre «iguales». 2.2. Derecho a la autonomía del usuario: consentimiento informado, por representación, por escrito, condiciones de la información, renuncia a la misma y límites. 2.3. Su aplicación a la práctica del tatuaje y piercing. VIII. CONTROL E INSPECCIÓN. 1. Una consideración preliminar. 1.1. El concepto de control. 1.2. El concepto de inspección. 2. Cometido asignado en este tipo de establecimientos. IX. RÉGIMEN SANCIONADOR. 1. Infracciones y sanciones: remisión al régimen sancionador de la Ley General de Sanidad. 2. Medidas cautelares. 3. Revocación de la autorización. X. CONCLUSIÓN.

\section{IDEAS GENERALES}

Es un hecho cierto la proliferación de las prácticas de tatuaje y perforación cutánea (piercing) a través de técnicas cruentas e invasivas que son realizadas en diversos tipos de centros o establecimientos, que en muchos casos carecen de condiciones higiénico-sanitarias adecuadas. Junto a esta realidad, es patente la existencia de personas que, sin formación alguna para aplicar estas técnicas, se dedican a esta actividad, lo que puede comportar consecuencias negativas para la salud de los usuarios de estos servicios y de las que los realizan. Por ello es necesario regular las condiciones de estos centros o establecimientos y delimitar y garantizar la formación adecuada de todos aquellos que se dedican a esta actividad, como medio para prevenir males mayores. Todo ello se lleva a cabo 
mediante el régimen de la autorización, el control y la inspección de los centros y establecimientos que de forma permanente o temporal, con carácter regular o esporádico, de modo estable o no estable realizan esta actividad, así como de sus instalaciones, material, instrumental y personal que desempeña esta labor. La consecuencia inmediata es que quedará prohibida la práctica de estas técnicas en aquellos espacios que incumplan las condiciones legalmente exigibles, dado el riesgo potencial de transmisión de enfermedades a través de la sangre asociada a prácticas como la decoración del cuerpo humano, a través de las heridas o pérdidas de revestimiento cutáneo. Y es así, porque no debe olvidarse la existencia de un riesgo asociado a las prácticas que implican la perforación de la piel o mucosas, realizados en ámbitos no sanitarios.

Sin embargo, antes de continuar con la exposición, debo mencionar, al menos, dos de las cuestiones que inicialmente sorprenden. La primera es la necesidad de estudiar si es un acierto o una incongruencia la aplicación de «normas sanitarias» a centros y establecimientos «no sanitarios». Y realizo esta afirmación, porque el sentido y finalidad de las disposiciones reglamentarias que regulan esta materia es la de excluir de su ámbito de aplicación los establecimientos, que, de conformidad con la legislación vigente, tienen la consideración de centros sanitarios ${ }^{1}$, es decir, aquellos donde se realizan prácticas consideradas procedimientos médicos, tales como los implantes bajo la piel, que deben ser realizadas exclusivamente en los centros, servicios y establecimientos sanitarios autorizados ${ }^{2}$. La segunda, y directamente relacionada con la primera es la atribución de la competencia para autorizarlos a las administraciones municipales, frente a las sanitarias. Del acierto o no de esta opción legislativa, intentaré dar cuenta a lo largo de estas páginas.

\section{DETERMINACIONES CONCEPTUALES}

Para intentar poner un poco de orden conceptual y metodológico es necesario y conveniente qué al menos se determine qué es un centro sani-

\footnotetext{
${ }^{1}$ Vide Orden 17/2003, de 14 de marzo, de la Consejería de Sanidad y Consumo de la Región de Murcia, que regula las condiciones higiénico-sanitarias de los establecimientos de tatuaje y de piercing de la Región de Murcia (BORM de 25 de marzo, núm. 69), art. 1.2.

2 Decreto 83/2002, de 23 de mayo, de la Consejería de Sanidad de la Generalitat Valenciana, por el que se determinan las normas que rigen la práctica del tatuaje, la micropigmentación, el piercing u otras técnicas similares y requisitos para la autorización y funcionamiento de los establecimientos donde se practican estas técnicas (DOGV de 29 de mayo, núm. 4259), art. 2.2.
} 
tario, que se entiende por «técnica», qué es un centro o establecimiento no sanitario donde se lleva a cabo el tatuaje y la perforación cutánea, cómo se definen estas prácticas y las distintas áreas que forman parte del establecimiento.

\section{Centro sanitario}

El concepto de centro sanitario ha sido abordado en mi monografía Creación y regulación de centros y establecimientos sanitarios, Bosch, Barcelona, 2003, p. 58, donde lo describo del siguiente modo: «Todo aquel bien mueble o inmueble en el que tras una correcta identificación, se aúnen los espacios físicos necesarios (área de recepción, sala de espera, área clínica, etc., uno o varios), el equipamiento y dotación de material y personal sanitario titulado, donde las técnicas o medios de carácter sanitario que utilizan tienen como finalidad principal o accesoria, ya sea preventiva, diagnóstica, terapéutica, rehabilitadora o didáctica, la curación o mejora de la salud del ciudadano y que previamente ha sido autorizado por la Administración sanitaria conforme a las disposiciones legales o reglamentarias vigentes para este fin». En esta obra mía abordo en profundidad una materia que de modo indirecto sirve para calibrar la regulación que ahora estudio.

\section{Técnica}

Para formular este concepto voy a remitirles a mi colaboración «Responsabilidad por acto sanitario y progreso de la «ciencia» o de la «técnica»», REDA, 104, (1999), y a la sentencia que allí comento: STS de 31 de mayo de 1999, Ponente: González Navarro:

«Y debe advertirse, además, que «estado de los conocimientos de la ciencia o de la técnica existentes» no es estado de la legislación, pues es sabido que ésta - la legislación, el derecho positivo - va siempre detrás de los hechos, hasta el punto de que no es infrecuente que se modifique un texto legal para adaptarlo al progreso técnico $[\ldots]$.

La técnica es, por lo pronto, un conjunto de actos específicos del hombre mediante los que éste consigue imponerse a la naturaleza, modificándola, venciéndola o anulándola; la técnica es a modo de un camino establecido por el hombre para alcanzar determinado fin, como puede ser vencer la enfermedad, en el caso que nos ocupa; y en este sentido podríamos decir que la técnica es un método para la aplicación de la ciencia [cuando ésta ha sido ya hecha] o para la práctica de una actividad artística; en el bien entendido - conviene advertirlo- de que la técnica unas veces sigue a la ciencia y otras veces la precede: lo primero cuando la ciencia existe ya, lo segundo 
cuando la ciencia está aún por hacer, situación ésta que puede darse por ejemplo, cuando el hombre conoce sólo los efectos de un fenómeno pero no sus causas ${ }^{3}$ [...]; y la técnica es también, y por último, equipamiento instrumental con que se cuenta para esa aplicación. Uno de los resultados que se obtiene del empleo de ese camino o método y de la utilización de ese equipamiento es el saber experimental, el saber práctico $[\ldots] »$.

\section{Establecimiento de tatuaje o piercing, áreas del mismo, técnicas aplicadas y personal que las desarrolla}

- Establecimiento de tatuaje o piercing: establecimiento no sanitario 4 donde se llevan a cabo actividades de tatuaje o piercing o cualquiera otros de naturaleza similar, ya sea con carácter exclusivo o integrado en centros donde se realicen otras actividades ${ }^{5}$. En el mismo es posible diferenciar: Área de espera: dependencia del establecimiento con espacio e instalaciones suficientes para asegurar al usuario una eventual espera previa con un grado de comodidad adecuado ${ }^{6}$; Área de trabajo: dependencia del establecimiento donde específicamente se realizan las actividades de tatuaje o piercing ${ }^{7}$; Área de preparación del material: zona diferenciada del establecimiento donde se realiza la limpieza, desinfección y esterilización del material ${ }^{8}$; Esterilización: es la completa eliminación o destrucción de

\footnotetext{
${ }^{3}$ La sentencia está pensando en casos como el que expone José María RiAZA, Ciencia moderna y filosofía. Introducción físicoquímica y matemática, 3. a edición, Biblioteca de autores cristianos, Madrid, 1969, p. 225: «Nada se supo de la naturaleza de los Rx en la 1. ${ }^{a}$ década después de su descubrimiento. Estaban ya generalizadas sus aplicaciones médicas y muy perfeccionada su técnica y aun se carecía de todo conocimiento acerca de su naturaleza». Debo recordar que W.C. RöNTGEN, de la Universidad de Wurzburgo, haciendo experiencias en 1895 con un tubo de Crookes de rayos catódicos, descubrió casualmente el 8 de noviembre unas radiaciones a las que llamó «Rayos X», por ser una incógnita su naturaleza.

${ }^{4}$ Sobre el concepto de establecimiento sanitario vide Juan Francisco Pérez Gálvez, Creación y regulación de centros y establecimientos sanitarios, Bosch, Barcelona, 2003, pp. 64-68.

${ }^{5}$ Vide Decreto 160/2002, de 30 de abril, del Departamento de Salud, Consumo y Servicios Sociales de Aragón, por el que se establecen las normas sanitarias aplicables a establecimientos de tatuajes (BOA de 20 de mayo, núm. 58; rect. BOA 20 de enero de 2003, núm. 7), art. 2; Orden 17/2003, de 14 de marzo, de la Consejería de Sanidad y Consumo de Murcia, art. 2; Decreto 28/2001, de 23 de enero, del Departamento de Sanidad y Seguridad Social de la Generalitat de Catalunya (BOGC 1 de febrero, núm. 3318), art. 2.

${ }^{6}$ Vide Orden 17/2003, de 14 de marzo, de la Consejería de Sanidad y Consumo de Murcia, art. 2.

${ }^{7}$ Vide Decreto 160/2002, de 30 de abril, del Departamento de Salud, Consumo y Servicios Sociales de Aragón, art. 2; Orden 17/2003, de 14 de marzo, de la Consejería de Sanidad y Consumo de Murcia, art. 2; Decreto 28/2001, de 23 de enero, del Departamento de Sanidad y Seguridad Social de la Generalitat de Catalunya, art. 2; Decreto Foral 132/2002, de 17 de junio, art. 2.
}

${ }^{8}$ Vide Orden 17/2003, de 14 de marzo, de la Consejería de Sanidad y Consumo de Murcia, art. 2. 
todas las formas de vida microbiana ${ }^{9}$; Desinfección: proceso de eliminación de los microorganismos patógenos pero no necesariamente de todas las formas microbianas ${ }^{10}$.

- Tatuaje: técnica o procedimiento de decoración del cuerpo humano con dibujos consistente en la introducción de pigmentos inertes en la piel, por medio de punciones con agujas u otros instrumentos y de micropigmentación ${ }^{11}$, con resultado de la coloración permanente ${ }^{12}$.

- Perforación cutánea (piercing): técnica o actividad consistente en la decoración del cuerpo humano, mediante la perforación con agujas u otros instrumentos punzantes, de la piel, mucosas u otros tejidos humanos, con el fin de colocar en la abertura obtenida un objeto (joyas u ornamentos). Se exceptúa la perforación del lóbulo de la oreja siempre que se realice con técnicas estériles o instrumental de un solo uso ${ }^{13}$.

- Aplicadores de tatuajes o piercing: personal que realiza actividades que implican la perforación de la piel, mucosas y/u otros tejidos ${ }^{14}$.

${ }^{9}$ Vide Decreto Foral 132/2002, de 17 de junio, art. 2.

${ }^{10}$ Vide Decreto Foral 132/2002, de 17 de junio, art. 2.

${ }^{11}$ Vide Real Decreto 198/1996, de 9 de febrero, del Ministerio de Educación y Ciencia, que determina el currículo del ciclo formativo de grado superior correspondiente al título de Técnico Superior en Estética ( $B O E$ de 13 de marzo, núm. 63), art. 3, que incluye como módulos profesionales del segundo curso: «d) Microimplantación de pigmentos».

12 Vide Decreto 286/2002, de 26 de noviembre, de la Consejería de Salud de la Junta de Andalucía, por el que se regulan las actividades relativas a la aplicación de técnicas de tatuaje y perforación cutánea (piercing) (BOJA de 7 de diciembre, núm. 144), pp. 23.809 y ss., art. 4; Decreto 160/2002, de 30 de abril, del Departamento de Salud, Consumo y Servicios Sociales de Aragón, art. 2; Orden 17/2003, de 14 de marzo, de la Consejería de Sanidad y Consumo de Murcia, art. 2; Decreto 28/2001, de 23 de enero del Departamento de Sanidad y Seguridad Social de la Generalitat de Catalunya, art. 2; Decreto Foral 132/2002, de 17 de junio, del Gobierno de Navarra, que establece las condiciones higiénico-sanitarias que han de cumplir los establecimientos no sanitarios en los que se realicen prácticas de tatuaje y/o piercing (BON de 9 de agosto, núm. 96), art. 2; Decreto $83 / 2002$, de 23 de mayo, de la Consejería de Sanidad de la Generalitat Valenciana, que determina las normas que rigen la práctica del tatuaje, la micropigmentación, el piercing u otras técnicas similares y requisitos para la autorización y funcionamiento de los establecimientos donde se practican estas técnicas ( $D O G V$ de 29 de mayo, núm. 4259), art. 2.1a).

${ }^{13}$ Vide Decreto 286/2002, de 26 de noviembre, de la Consejería de Salud de la Junta de Andalucía, por el que se regulan las actividades relativas a la aplicación de técnicas de tatuaje y perforación cutánea (piercing), art. 4; Decreto 160/2002, de 30 de abril, del Departamento de Salud, Consumo y Servicios Sociales de Aragón, art. 2; Orden 17/2003, de 14 de marzo, de la Consejería de Sanidad y Consumo de Murcia, art. 2; Decreto 28/2001, de 23 de enero, del Departamento de Sanidad y Seguridad Social de la Generalitat de Catalunya, art. 2; Decreto Foral 132/2002, de 17 de junio, art. 2.

${ }^{14}$ Vide Decreto 160/2002, de 30 de abril, del Departamento de Salud, Consumo y Servicios Sociales de Aragón, art. 2; Orden 17/2003, de 14 de marzo, de la Consejería de Sanidad y Consumo de 


\section{NATURALEZA}

La propia regulación de este tipo de establecimientos los cataloga como no sanitarios. Por tanto, desde el punto de vista formal nada más puedo añadir. Sin embargo, las técnicas empleadas, las condiciones generales que deben cumplir los locales donde se desarrolla esta actividad, su distribución funcional, el equipamiento e instrumental utilizado, la preparación exigible a los profesionales que desempeñan esta labor, así como la necesidad de contar con la aprobación expresa del usuario, ponen en tela de juicio una declaración tan rotunda como la empleada para definir a estos establecimientos.

\section{CLASIFICACIÓN}

La clasificación sobre este tipo de centros o establecimientos puede efectuarse en base a dos criterios. En primer lugar, atendiendo a las técnicas empleadas. Lo que da lugar a diferenciar entre aquellos donde se realiza tatuaje, piercing, o ambas a la vez. También es posible clasificarlos si las mismas se desarrollan de modo habitual o esporádico, o de modo exclusivo o conjunto con otras. En segundo lugar, podría clasificarlos en virtud del carácter estable o no del establecimiento. Y efectúo esta afirmación, porque cuando con motivo de ferias, congresos u otros acontecimientos similares se realicen actividades de tatuaje o piercing en instalaciones no estables, éstas deberán cumplir condiciones sanitarias equivalentes a las establecidas para las estables ${ }^{15}$. Incluso alguna Comunidad Autónoma prohíbe que los servicios que utilicen materiales destinados a penetrar en la piel se puedan realizar en establecimientos de carácter ambulante ${ }^{16}$.

\section{GRUPO NORMATIVO REGULADOR}

\section{Estatal}

La LBRL establece en el artículo 25.2.h) lo siguiente: «El Municipio ejercerá, en todo caso, competencias en los términos de la legislación del

\footnotetext{
Murcia, art. 2; Decreto 28/2001, de 23 de enero, del Departamento de Sanidad y Seguridad Social de la Generalitat de Catalunya, art. 2; Decreto Foral 132/2002, de 17 de junio, art. 2.

15 Vide Decreto 160/2002, de 30 de abril, del Departamento de Salud, Consumo y Servicios Sociales de Aragón, art. 3.2; Orden 17/2003, de 14 de marzo, de la Consejería de Sanidad y Consumo de Murcia, arts. 3.2 y 4.1; Decreto 83/2002, de 23 de mayo, art. 3.8.
}

16 Vide Decreto Foral 132/2002, de 17 de junio, art. 9. 
Estado y de las Comunidades Autónomas en las siguientes materias: h) Protección de la salubridad pública». Además, podrá ejercitar otras competencias delegadas siempre que afecten a sus intereses propios, se mejore con ello la eficacia de la gestión y se alcance una mayor participación ciudadana.

La Ley 14/1986, de 25 de abril, General de Sanidad, dictada al amparo de lo previsto en el artículo 149.1.16. ${ }^{a} \mathrm{CE}$, establece en su artículo 24: «Las actividades públicas y privadas que, directa o indirectamente, puedan tener consecuencias negativas para la salud serán sometidas por los órganos competentes a limitaciones preventivas de carácter administrativo, de acuerdo con la normativa básica del Estado».

Sobre esta base jurídica, los municipios tienen competencias propias en esta materia, circunstancia que no se coordina mucho con el contenido del artículo 42 de la $\mathrm{LGS}^{17}$, que no otorga un ámbito competencial propio a los entes locales en materia de salud pública, sino que le atribuye responsabilidades en materia de salubridad (control sobre edificios y viviendas) ${ }^{18}$.

${ }^{17}$ Vide LGS, art. 42: «1. Las normas de las Comunidades Autónomas, al disponer sobre la organización de sus respectivos servicios de salud, deberán tener en cuenta las responsabilidades y competencias de las provincias, municipios y demás Administraciones Territoriales intracomunitarias, de acuerdo con lo establecido en los Estatutos de Autonomía, la Ley de Régimen Local y la presente Ley.

2. Las Corporaciones Locales participarán en los órganos de dirección de las Áreas de Salud.

3. No obstante, los Ayuntamientos, sin perjuicio de las competencias de las demás Administraciones Públicas, tendrán las siguientes responsabilidades mínimas en relación al obligado cumplimiento de las normas y planes sanitarios: a) Control sanitario del medio ambiente: contaminación atmosférica, abastecimiento de aguas, saneamiento de aguas residuales, residuos urbanos e industriales. b) Control sanitario de industrias, actividades y servicios, transportes, ruidos y vibraciones. c) Control sanitario de edificios y lugares de vivienda y convivencia humana, especialmente de los centros de alimentación, peluquerías, saunas y centros de higiene personal, hoteles y centros residenciales, escuelas, campamentos turísticos y áreas de actividades físico-deportivas y de recreo. d) Control sanitario de la distribución y suministro de alimentos, bebidas y demás productos, directa o indirectamente relacionados con el uso o consumo humanos, así como los medios de su transporte. e) Control sanitario de los cementerios y policía sanitaria mortuoria.

4. Para el desarrollo de las funciones relacionadas en el apartado anterior, los Ayuntamientos deberán recabar el apoyo técnico del personal y medios de las Áreas de Salud en cuya demarcación estén comprendidos.

5. El personal sanitario de los Servicios de Salud de las Comunidades Autónomas que presten apoyo a los Ayuntamientos en los asuntos relacionados en el apartado tres, tendrá la consideración, a estos solos efectos, de personal al servicios de los mismos, con sus obligadas consecuencias en cuanto a régimen de recursos y responsabilidad personales y patrimoniales».

18 Vide Manuel BEATo EsPEJo, «El sistema sanitario español: su configuración en la Ley General de Sanidad», RAP, 119, (1989), pp. 416-418. 
REAL 291 (HOMENAJE AL PROFESOR SEBASTIÁN MARTÍN-RETORTILLO)

\section{Autonómico}

Tendría que hacer referencia a los distintos Estatutos de Autonomía (normas que emanan de las Cortes Generales), las distintas leyes autonómicas de régimen local que reproducen lo determinado en la Ley de Bases del Estado, así como a las respectivas leyes de salud autonómicas. En las mismas se precisa que en materia de salud pública (sería más preciso el término «salubridad»), los municipios ejercerán las competencias que tienen atribuidas, según las condiciones previstas en la legislación de régimen local. Sin perjuicio de las competencias de las demás Administraciones Públicas, tendrán las siguientes responsabilidades, entre otras, en relación al obligado cumplimiento de las normas y los planes sanitarios:

- Control sanitario de industrias, actividades, servicios y transportes ${ }^{19}$.

- Control sanitario de edificios y lugares de vivencia y convivencia humana, especialmente de los centros de alimentación, peluquerías, saunas y centros de higiene corporal, hoteles y centros residenciales, escuelas y campamentos turísticos y áreas de actividad física, deportiva y de recreo ${ }^{20}$.

\footnotetext{
19 Vide Ley 2/1998, de 15 de junio, de Salud de Andalucía (BOJA de 4 de julio, núm. 74), art. 38.1b); Ley 6/2002, de 15 de abril, de Salud de Aragón (BOE de 21 de mayo, núm. 121), art. 61.1.Ab); Ley 11/1994, de 26 de julio, de Ordenación Sanitaria de Canarias (BOCAN de 5 de agosto, núm. 96), art. 47.1b); Ley 7/2002, de 10 de diciembre, de Ordenación Sanitaria de Cantabria (BOE de 7 de enero de 2003, núm 6), art. 60.2b); Ley 8/2000, de 30 de noviembre, de Ordenación Sanitaria de Castilla-La Mancha (BOCM de 19 de diciembre, núm. 126), art. 66.1.Ab); Ley 1/1993, de 6 de abril, de Ordenación del Sistema Sanitario de Castilla y León (BOCyL de 27 de abril, núm. 77), art. 57.1b); Ley 15/1990, de 9 de julio, de Ordenación Sanitaria de Cataluña (DOGC de 30 de julio, núm. 1324), art. 68.1b); Ley 7/2003, de 25 de abril, de Protección de la Salud de Cataluña (DOGC de 8 de mayo, núm. 3879), art. 45.1d); Ley 10/2001, de 28 de junio, Normas reguladoras de la Salud de Extremadura ( $D O E$ de 3 de julio, núm. 76), art. 9.1b); Ley 12/2001, de 21 de diciembre, de Ordenación Sanitaria de Madrid (BOCM de 26 de diciembre, núm. 306), art. 137.1c); Ley 4/1994, de 26 de julio, Normas reguladoras de la Sanidad en Murcia (BORM de 4 de agosto, núm. 178), art. 7.1b); Ley Foral 10/1990, de 23 de noviembre, Normas reguladoras de la Salud (BON de 3 de diciembre, núm. 146), art. 34.1b); Ley 2/2002, de 17 de abril, de Salud de La Rioja (BOE de 3 de mayo, núm. 106), art. 71.1b); Ley 3/2003, de 6 de febrero, de Ordenación Sanitaria de la Comunidad Valenciana (BOE de 5 de marzo, núm. 55), art. 5.
}

${ }^{20}$ Vide Ley 2/1998, de 15 de junio, de Salud de Andalucía, art. 38.1c); Ley 6/2002, de 15 de abril, de Salud de Aragón, art. 61.1.Ac); Ley 11/1994, de 26 de julio, de Ordenación Sanitaria de Canarias, art. 47.1c); Ley 7/2002, de 10 de diciembre, de Ordenación Sanitaria de Cantabria, art. 60.2c); Ley 8/2000, de 30 de noviembre, de Ordenación Sanitaria de Castilla-La Mancha, art. 66.1.Ac); Ley 1/1993, de 6 de abril, de Ordenación del Sistema Sanitario de Castilla y León, art. 57.1c); Ley 15/1990, de 9 de julio, de Ordenación Sanitaria de Cataluña, art. 68.1b); Ley 10/2001, de 28 de junio, Normas reguladoras de la Salud de Extramadura, art. 9.1c); Ley 12/2001, de 21 de diciembre, de Ordenación Sanitaria de Madrid, art. 137.1d); Ley 4/1994, de 26 de julio, Normas reguladoras de la Sanidad de Murcia, art. 7.1c); Ley Foral 10/1990, de 23 de noviembre, Normas reguladoras de la Salud en Navarra, art. 34.1c); Ley 2/2002, de 17 de abril, de Salud de La Rioja, art. 71.1c); Ley 3/2003, de 6 de febrero, de Ordenación Sanitaria de la Comunidad Valenciana, art. 5. 


\section{Local $^{21}$}

Las competencias de las entidades locales en materia sanitaria deben encuadrarse jurídicamente en el marco de la legislación estatal, sus respectivos Estatutos de Autonomía y en las disposiciones que ellas mismas puedan dictar para el ejercicio de las competencias y funciones que tienen encomendadas, que serán de aplicación en su ámbito territorial $^{22}$.

Cuando el desarrollo de las funciones sanitarias lo requiera, los municipios podrán disponer de personal para el ejercicio de sus competencias. En aquellos donde el desarrollo de tales funciones no justifique la existencia de este personal, deberán recabar el apoyo técnico del personal y medios de las áreas de salud en cuya demarcación estén comprendidos ${ }^{23}$. El personal sanitario de la respectiva Comunidad Autónoma que preste apoyo a los municipios en estas materias, tendrá la consideración de personal al servicio de los mismos, con sus obligadas consecuencias en cuanto a régimen de recursos y responsabilidades personales y patrimoniales ${ }^{24}$.

21 Vide Francisco Sosa Wagner, «La autonomía municipal», RAP, 100-102, (1983), pp. 22392253; Juan Luis Beltrán AgUiRRe, «Las competencias de las Entidades Locales de Navarra en materia de Sanidad», Revista Jurídica de Navarra, 2, (1986), pp. 103-117.

${ }^{22}$ Vide Ley 2/1998, de 15 de junio, de Salud de Andalucía, art. 39; Ley 7/2002, de 10 de diciembre, de Ordenación Sanitaria de Cantabria, art. 60.4; Ley Foral 10/1990, de 23 de noviembre, Normas reguladoras de la Salud en Navarra, art. 36.1.

${ }^{23}$ Vide Ley 2/1998, de 15 de junio, de Salud de Andalucía, art. 40; Ley 6/2002, de 15 de abril, de Salud de Aragón, arts. 61.2 y 3; Ley 1/1992, de 2 de julio, de Creación del Servicio de Salud del Principado de Asturias (BOPA de 13 de julio, núm. 162), art. 46.3; Ley 5/2003, de 4 de abril, Ley de Salud de las Islas Baleares (BOIB de 22 de abril, núm. 55), art. 48.3; Ley 7/2002, de 10 de diciembre, de Ordenación Sanitaria de Cantabria, art. 60.5; Ley 8/2000, de 30 de noviembre, de Ordenación Sanitaria de Castilla-La Mancha, art. 66.2; Ley 1/1993, de 6 de abril, de Ordenación del Sistema Sanitario de Castilla y León, art. 57.4; Ley 15/1990, de 9 de julio, de Ordenación Sanitaria de Cataluña, art. 68.2; Ley 7/2003, de 25 de abril, de Protección de la Salud de Cataluña, art. 45.2; Ley 10/2001, de 28 de junio, Normas reguladoras de la Salud de Extremadura, art. 9.3; Ley 4/1994, de 26 de julio, Normas reguladoras de la Sanidad de Murcia, art. 8.1; Ley Foral 10/1990, de 23 de noviembre, Normas reguladoras de la Salud de Navarra, art. 36.2; Ley 2/2002, de 17 de abril, de Salud de La Rioja, art. 71.3; Ley 3/2003, de 6 de febrero, de Ordenación Sanitaria de la Comunidad Valenciana, art. 5.

${ }^{24}$ Vide Ley 2/1998, de 15 de junio, de Salud de Andalucía, art. 41; Ley 6/2002, de 15 de abril, de Salud de Aragón, arts. 61.4; Ley 1/1992, de 2 de julio, de Asturias, art. 46.3; Ley 7/2002, de 10 de diciembre, de Ordenación Sanitaria de Cantabria, art. 60.6; ley 1/1993, de 6 de abril, de Ordenación del Sistema Sanitario de Castilla y León, art. 57.4; Ley 4/1994, de 26 de julio, Normas reguladoras de la Sanidad de Murcia, art. 8.2; Ley Foral 10/1990, de 23 de noviembre, Normas reguladoras de la Salud en Navarra, art. 36.2. 


\section{CARACTERÍSTICAS DE LOS CENTROS Y ESTABLECIMIENTOS}

Los titulares de los establecimientos donde se realizan estas técnicas son los responsables de las actividades que allí se realizan, así como de la higiene, seguridad y mantenimiento de las instalaciones, equipo e instrumental en las condiciones determinadas reglamentariamente. También son responsables de garantizar la aplicación de las medidas para la protección de la salud de los usuarios y del personal que los realiza ${ }^{25}$.

\section{Condiciones generales de los locales}

Las distintas regulaciones de esta materia establecen la necesidad de que los locales donde se realicen las actividades de tatuaje y perforación cutánea deben mantenerse en estado de limpieza, desinfección y uso correcto y deberán estar ventilados y protegidos del polvo y de la humedad. Si disponen de ventanas o rejillas de ventilación estarán protegidas con mallas antinsectos. De forma periódica se desinfectarán todas sus superficies. Asimismo, el diseño y los materiales que constituyen el mobiliario de las dependencias destinadas a las actividades han de ser fáciles de limpiar y desinfectar. Los elementos metálicos de las instalaciones han de ser materiales resistentes a la oxidación. El material necesario para las actividades de aplicación de estas técnicas ha de estar dispuesto de manera que el acceso del personal aplicador al instrumental necesario sea fácil y con el menor desplazamiento posible ${ }^{26}$.

\section{Distribución funcional}

Los establecimientos destinados a estas prácticas deberán contar al menos con las siguientes áreas diferenciadas:

\footnotetext{
${ }^{25}$ Vide Decreto 83/2002, de 23 de mayo, de la Consejería de Sanidad de la Generalitat Valenciana, art. 11.

${ }^{26}$ Vide Decreto 286/2002, de 26 de noviembre, de la Consejería de Salud de la Junta de Andalucía, art. 5; Decreto 160/2002, de 30 de abril, del Departamento de Salud, Consumo y Servicios Sociales de Aragón, art. 3; Orden 17/2003, de 14 de marzo, de la Consejería de Sanidad y Consumo de Murcia, art. 5.1; Decreto 28/2001, de 23 de enero, del Departamento de Sanidad y Seguridad Social de la Generalitat de Catalunya, arts. 4 y 5.2; Decreto Foral 132/2002, de 17 de junio, arts. 4.1, 4.9 y 4.11; Decreto 83/2002, de 23 de mayo, art. 3.1.
} 
- Área de recepción e información: destinada a las relaciones comerciales con el usuario y con condiciones adecuadas para procurar su comodidad $^{27}$.

- Área de trabajo: destinada a la práctica de las técnicas de tatuaje y perforación cutánea. Deberá estar bien iluminada y los dispositivos de iluminación estarán protegidos contra roturas, aislada del resto del establecimiento y deberá disponer de un lavamanos de accionamiento no manual, equipado con agua corriente, jabón, toallas de un sólo uso y cepillo de uñas. Las superficies (suelos, paredes y techos) del área de trabajo deben ser lisas y lavables, y permitir una adecuada limpieza y desinfección ${ }^{28}$. No se admitirá el acceso de animales ${ }^{29}$, ni su permanencia en el área de trabajo ${ }^{30}$.

- Área de esterilización: destinada a la limpieza, esterilización, desinfección y preparación del instrumental. Esta área debería contar con una superficie de material liso e impermeable, fácil de limpiar y desinfectar y en ella existirán dos zonas diferenciadas: a) Una zona destinada a colocar los materiales pendientes de limpieza, desinfección y/o esterilización; b) Una zona donde realizar la limpieza, desinfección o esterilización del material ${ }^{31}$. Esta zona se considerará de acceso restringido al público ${ }^{32}$.

- Aseo: para uso de los clientes con inodoro y lavamanos con agua corriente y elementos de higiene necesarios ${ }^{33}$.

${ }^{27}$ Vide Decreto 286/2002, de 26 de noviembre, de la Consejería de Salud de la Junta de Andalucía, art. 6.1.b); Decreto Foral 132/2002, de 17 de junio, art. 3.1a).

${ }^{28}$ Vide Decreto 286/2002, de 26 de noviembre, de la Consejería de Salud de la Junta de Andalucía, art. 6.1.a); Orden 17/2003, de 14 de marzo, de la Consejería de Sanidad y Consumo de Murcia, art. 5.2; Decreto 28/2001, de 23 de enero, del Departamento de Sanidad y Seguridad Social de la Generalitat de Catalunya, art. 5.1; Decreto Foral 132/2002, de 17 de junio, art. 3.1b); Decreto 83/2002, de 23 de mayo, de la Consejería de Sanidad de la Generalitat Valenciana, arts. 3.2 y 3.3.

${ }^{29}$ Vide Decreto 286/2002, de 26 de noviembre, de la Consejería de Salud de la Junta de Andalucía, art. 6.2; Decreto 28/2001, de 23 de enero, del Departamento de Sanidad y Seguridad Social de la Generalitat de Catalunya, art. 5.3.

${ }^{30}$ Decreto 83/2002, de 23 de mayo, de la Consejería de Sanidad de la Generalitat Valenciana, art. 3.5.

${ }^{31}$ Vide Decreto 286/2002, de 26 de noviembre, de la Consejería de Salud de la Junta de Andalucía, art. 6.1.c); Orden 17/2003, de 14 de marzo, de la Consejería de Sanidad y Consumo de Murcia, art. 5.3.

32 Vide Decreto 286/2002, de 26 de noviembre, de la Consejería de Salud de la Junta de Andalucía, art. 6.4.

${ }^{33}$ Vide Decreto Foral 132/2002, de 17 de junio, art. 3.1.c); Decreto 83/2002, de 23 de mayo, art. 3.6. 
En el caso de compartir locales con espacios destinados a vivienda, comercio o a otras prácticas de atención personal, el área de trabajo deberá ubicarse diferenciándose claramente de las mismas, mediante separación física y funcional ${ }^{34}$.

\section{Equipo e instrumental}

Los instrumentos y materiales que se utilicen, y que por tanto entren en contacto con las personas, han de estar limpios, desinfectados y en buen estado de conservación. Deberán permitir su esterilización o desinfección y se conservará en condiciones de asepsia hasta el momento de su utilización. Los que sean de un solo uso deberán conservarse de forma adecuada y ser desechados tras su utilización ${ }^{35}$.

Los objetos utilizados para adornos, así como agujas, jeringas, pigmentos u otros elementos y materiales que atraviesen la piel, las mucosas u otros tejidos han de estar siempre esterilizados o ser de un solo uso, incluidos los elementos de rasurar y afeitar ${ }^{36}$. No se pueden utilizar los denominados lápices cortasangre, ni las pistolas perforadoras, cuyo uso queda restringido a la perforación del lóbulo de la oreja ${ }^{37}$. La

\footnotetext{
${ }^{34}$ Vide Decreto Foral 132/2002, de 17 de junio, art. 3.2.

${ }^{35}$ Vide Decreto 286/2002, de 26 de noviembre, de la Consejería de Salud de la Junta de Andalucía, art. 7.1. En el Anexo I determina los métodos de esterilización: «Son apropiados los siguientes métodos para la esterilización: 1 . El autoclave a vapor a $120^{\circ} \mathrm{C}$ y una atmósfera de presión durante 20 minutos, u otras combinaciones equivalentes. 2. Calor seco a $170^{\circ} \mathrm{C}$ durante 60 minutos u otras combinaciones equivalentes». En el Anexo II señala los métodos de limpieza y desinfección: «Son apropiados los siguientes métodos de limpieza y desinfección: 1. Inmersión en una solución al $2 \%$ de glutaraldehido durante 30 minutos. 2. Inmersión en una solución al 20\% V/V de lejía (de 50 gr. de cloro por litro) durante 30 minutos. 3. Inmersión en alcohol etílico al 70\% durante 30 minutos»; Decreto 160/2002, de 30 de abril, del Departamento de Salud, Consumo y Servicios Sociales de Aragón, art. 4; Orden 17/2003, de 14 de marzo, de la Consejería de Sanidad y Consumo de Murcia, art. 6; Decreto 28/2001, de 23 de enero, del Departamento de Sanidad y Seguridad Social de la Generalitat de Catalunya, arts. 7.1, 7.5 y 7.6; Decreto Foral 132/2002, de 17 de junio, art. 4.
}

${ }^{36}$ Vide Decreto 286/2002, de 26 de noviembre, de la Consejería de Salud de la Junta de Andalucía, art. 7.2. En el Anexo III determina los materiales aceptados para joyas tras perforación cutánea: «1. Los materiales han de ser de una calidad mínima que evite el riesgo de reacciones alérgicas, habrán de ser biocompatibles y de materiales reconocidos como aptos para implantes subcutáneos por la normativa vigente (Directiva 94/27/CE del Parlamento Europeo y el Consejo de la Unión Europea). 2. En los procedimientos de perforación cutánea (piercing), las joyas utilizadas serán de acero inoxidable, oro de 14 quilates, como mínimo, o titanio para reducir el riesgo de infección o reacción alérgica». Vide Orden 17/2003, de 14 de marzo, de la Consejería de Sanidad y Consumo de Murcia, arts. 6.3 y 6.4 .

${ }^{37}$ Vide Decreto 286/2002, de 26 de noviembre, de la Consejería de Salud de la Junta de Andalucía, art. 7.3; Orden 17/2003, de 14 de marzo, de la Consejería de Sanidad y Consumo de Murcia, 
camilla utilizada se cubrirá con un material que evite el contacto directo con el cuerpo del usuario, de forma que se garanticen unas condiciones higiénico-sanitarias adecuadas, y que se cambiará tras cada aplicación ${ }^{38}$. Las tintas para tatuaje se adquirirán estériles y en presentaciones para aplicación única, utilizándose un envase de tinta para una aplicación y para una persona. La tinta sobrante deberá ser desechada después de su uso ${ }^{39}$. El titular del establecimiento deberá garantizar el origen y la composición de los productos de tatuaje y de los objetos para piercing que se apliquen ${ }^{40}$.

Todos los establecimientos dedicados a esta actividad deberán disponer de un botiquín y contar con el equipamiento mínimo con la dotación que reglamentariamente se determine ${ }^{41}$.

art. 6.5; Decreto 28/2001, de 23 de enero, del Departamento de Sanidad y Seguridad Social de la Generalitat de Catalunya, arts. 7.2, 7.3 y 7.4; Decreto Foral 132/2002, de 17 de junio, art. 4; Decreto $83 / 2002$, de 23 de mayo, art. 6 .

38 Vide Orden 17/2003, de 14 de marzo, de la Consejería de Sanidad y Consumo de Murcia, art. 6.8 .

39 Vide Orden 17/2003, de 14 de marzo, de la Consejería de Sanidad y Consumo de Murcia, art. 6.11; Decreto Foral 132/2002, de 17 de junio, art. 4.8.

40 Vide Orden 17/2003, de 14 de marzo, de la Consejería de Sanidad y Consumo de Murcia, art. 4.4.

${ }^{41}$ Vide Decreto 286/2002, de 26 de noviembre, de la Consejería de Salud de la Junta de Andalucía, art. 7.6, donde determina que se revisará mensualmente para verificar la fecha de caducidad y se repondrá inmediatamente el material usado. En el Anexo V determina: «1. Contenido mínimo: a) Desinfectantes y antisépticos. b) Gasas estériles. c) Algodón hidrófilo. d) Venda. e) Esparadrapo. f) Apósitos adhesivos. g) Tijeras. h) Pinzas. i) Guantes desechables. 2. Consideraciones generales a los botiquines: a) Han de contener exclusivamente material de primeros auxilios. b) El contenido ha de estar ordenado. c) Se ha de reponer el material usado y verificar la fecha de caducidad. d) El contenido ha de estar acorde con el nivel de formación del aplicador». Vide Decreto 160/2002, de 30 de abril, del Departamento de Salud, Consumo y Servicios Sociales de Aragón, art. 4.7; Orden 17/2003, de 14 de marzo, de la Consejería de Sanidad y Consumo de Murcia, arts. 6.9 y 6.10. Esta última disposición en el Anexo III, determina el equipamiento mínimo necesario para este tipo de establecimientos: «Limpiador de ultrasonidos. Cubetas para inmersión de material. Cubetas esterilizables para depositar la tinta. Testigos de control de esterilización. Esterilizador de vapor o de calor seco con control manual. Fundas o estuches para el material a esterilizar. Bandeja de metal para colocar los juegos de material estéril, instrumental o equipo limpio previo al tratamiento de tatuaje o piercing. Depósitos con tapa para colocar artículos limpios. Guantes tipo quirúrgico desechables. Depresores o espátulas de un solo uso. Envoltorios o contenedores apropiados para instrumentos pendientes de esterilizar. Contenedor de residuos punzantes y cortantes. Contenedor de residuos químicos. Guantes desechables de limpieza. Detergente de limpieza. Desinfectante. Material para cubrir la camilla». Vide Decreto 28/2001, de 23 de enero, del Departamento de Sanidad y Seguridad Social de la Generalitat de Catalunya, art. 7.7; Decreto 83/2002, de 23 de mayo, de la Consejería de Sanidad de la Generalitat Valenciana, art. 9. 


\section{Personal}

\subsection{Requisitos relativos al personal aplicador de técnicas de tatuaje y perforación cutánea}

El personal deberá tener la formación adecuada para la realización de estas prácticas sin riesgo para la salud y estar vacunado de Hepatitis B y Tétanos. Asimismo, deberá cumplir las normas de higiene propias de estas técnicas ${ }^{42}$.

\subsection{Formación}

\subsubsection{Obligación de formación del personal}

El personal aplicador de estas técnicas deberá disponer de un nivel de conocimientos suficientes para realizar una prevención efectiva de los riesgos para la salud, derivados de estas actividades. Para ello deberá superar ostentar la titulación que sea exigible ${ }^{43}$ o los correspondientes cursos de formación, con la duración mínima que reglamentariamente se determine. Las entidades organizadoras de los mismos, acreditarán el aprovecha-

\footnotetext{
${ }^{42}$ Vide Decreto 286/2002, de 26 de noviembre, de la Consejería de Salud de la Junta de Andalucía, art. 8.1. En el art. 8.2 precisa las normas de higiene a que he hecho referencia: «a) Lavarse las manos con agua y jabón antes de iniciar cualquier práctica y al finalizar la misma, así como cada vez que dicha práctica se reemprenda, en caso de haber sido interrumpida. b) Utilizar guantes de un solo uso. c) Cubrirse los cortes, heridas, quemaduras u otras lesiones infecciosas o inflamatorias de la piel con vendajes impermeables. Cuando esto no sea posible, se abstendrá de realizar prácticas que impliquen contacto directo con los usuarios, hasta que se produzca su curación. d) Esterilizar, desinfectar o sustituir, según proceda, el instrumental que se sospeche que haya podido contaminarse por cualquier eventualidad durante la aplicación de estas técnicas». Vide Decreto 160/2002, de 30 de abril, del Departamento de Salud, Consumo y Servicios Sociales de Aragón, art. 5, donde además de lo expuesto en el Decreto andaluz adiciona, art. 5.5: «Los aplicadores deben utilizar ropa limpia y específica para su trabajo, que será sustituida siempre que se manche de sangre o fluidos corporales»; Orden 17/2003, de 14 de marzo, de la Consejería de Sanidad y Consumo de Murcia, art. 7; Decreto 28/2001, de 23 de enero, del Departamento de Sanidad y Seguridad Social de la Generalitat de Catalunya, art. 8; Decreto Foral 132/2002, de 17 de junio, art. 6; Decreto 83/2002, de 23 de mayo, de la Consejería de Sanidad de la Generalitat Valenciana, arts. 14 y 15 .

${ }^{43}$ Vide Decreto 83/2002, de 23 de mayo, de la Consejería de Sanidad de la Generalitat Valenciana, art. 12, donde se precisa: «Los profesionales que realizan actividades de tatuajes, piercing o micropigmentación deberán disponer de un nivel de conocimientos suficientes para realizar la prevención efectiva de los riesgos para la salud asociados a sus prácticas. Para ello deberán estar en posesión de la titulación de Técnico Superior en Estética o acreditar la superación de los correspondientes cursos de formación homologados por la Consellería de Sanidad o entidad en la que haya delegado esta atribución». Vide Orden de 27 de noviembre de 2002, de la Consejería de Sanidad de la Generalitat Valenciana, que regula el contenido básico de los cursos de formación higiénico-sanitarias, dirigido a profesionales del cuidado y estética corporal (DOGV de 29 de noviembre, núm. 4389).
} 
miento de la formación recibida por el personal, mediante la expedición de los certificados correspondientes, en los que se deberá hacer constar la referencia a la resolución de homologación concedida ${ }^{44}$.

\subsubsection{Homologación de cursos de formación}

Las entidades organizadoras de los cursos de formación para estas prácticas, deberán solicitar con anterioridad a su desarrollo la homologación de los mismos, a la Consejería de Salud, acompañando a la solicitud una memoria en la que se hagan constar al menos: a) Objetivos del curso. b) Contenidos del programa docente (teóricos y prácticos). c) Formación y experiencia profesional del personal docente. d) Calendario y horario. e) Instalaciones disponibles para la formación teórica y práctica. f) Datos de la persona física o jurídica responsable de la entidad solicitante. g) Condiciones de inscripción y número de plazas ofertadas. Además, dichas homologaciones deberán publicarse en el Boletín Oficial de la Comunidad Autónoma que lo apruebe ${ }^{45}$.

\subsubsection{Requisitos de los cursos de formación}

Los cursos de formación deberían incluir pruebas previas y posteriores, con la doble finalidad de conocer el estado de los conocimientos, antes del

\footnotetext{
44 Vide Decreto 286/2002, de 26 de noviembre, de la Consejería de Salud de la Junta de Andalucía, art. 10; Orden 17/2003, de 14 de marzo, de la Consejería de Sanidad y Consumo de Murcia, art. 8 , donde además precisa: «[...]. De la realización de dichos cursos quedarán eximidos aquellos aplicadores que cuenten con titulación oficial en cuyo programa de estudios se incluyan las materias relacionadas en el Anexo V»; Decreto 28/2001, de 23 de enero, del Departamento de Sanidad y Seguridad Social de la Generalitat de Catalunya, art. 11.1; Resolución 1886/2002, de 7 de marzo, del Departamento de Sanidad y Seguridad Social de la Generalitat de Catalunya (DOGC de 1 de julio, núm. 3667): «[...], El Instituto de Estudios de la Salud, con el informe previo del Director general de Salud Pública, puede determinar las equivalencias entre los contenidos formativos teóricos que establece este Decreto y los contenidos de los currículos que puedan presentar los aspirantes. De acuerdo con esta disposición, se propone que determinadas titulaciones profesionales sean eximidas de tener que solicitar la convalidación de los contenidos formativos de sus estudios con los exigidos en este curso formativo sobre los aspectos higiénico-sanitarios de las actividades profesionales de los aplicadores de tatuajes y/o piercings, ya que el contenido de sus formaciones está absolutamente relacionado y sobrepasa con creces los conocimientos exigidos en esta actividad formativa, [...]. Las titulaciones que son susceptibles de la exención [...] son: Licenciatura de Medicina y Cirugía; Licenciatura de Farmacia; Diplomatura en Enfermería».

45 Vide Decreto 286/2002, de 26 de noviembre, de la Consejería de Salud de la Junta de Andalucía, art. 11; Decreto 160/2002, de 30 de abril, del Departamento de Salud, Consumo y Servicios Sociales de Aragón, art. 6.2; Decreto 28/2001, de 23 de enero, del Departamento de Sanidad y Seguridad Social de la Generalitat de Catalunya, arts. 11.2 y 11.3; Decreto 83/2002, de 23 de mayo, de la Consejería de Sanidad de la Generalitat Valenciana, art. 13.
} 
estudio de los temas del programa, y evaluar la aptitud de los asistentes, una vez finalizado el temario. Se deberán incluir sesiones prácticas. Los contenidos deberán versar sobre materias generales y específicas ${ }^{46}$.

\section{Quejas y reclamaciones}

En el área de recepción e información deberá existir un «libro de quejas y reclamaciones» a disposición de los usuarios ${ }^{47}$. Sin duda es una consecuencia del catálogo de derechos de los pacientes recogidos en el artículo 10.12 LGS que no ha sido derogado:

«Todos tienen los siguientes derechos con respecto a las distintas administraciones públicas sanitarias: [...].

${ }^{46}$ Vide Decreto 286/2002, de 26 de noviembre, de la Consejería de Salud de la Junta de Andalucía, art. 12. En el anexo IV determina los contenidos y métodos básicos de los programas de formación:

«1. Test previo: Evaluación inicial del estado de conocimientos del alumnado.

\section{Temario:}

A) Temario común: Tendrá una duración de 20 horas, con el siguiente contenido mínimo: a) Régimen de responsabilidad civil: Nociones básicas. b) Técnicas de relajación y manejo del estrés: ideas fundamentales. c) Ideas fundamentales sobre anatomía y fisiología básica; enfermedades transmisibles. d) Primeros auxilios, generalidades: - Desvanecimiento del cliente (Hipoglucemia, hipotensión, estrés, $[\ldots])$. - Protocolos de actuación del aplicador. e) Higiene de los procedimientos: - Limpieza, desinfección y asepsia, conceptos diferenciales. —Esterilización y desinfección: conceptos y métodos. —Protocolo de aplicación de tatuaje y perforación cutánea (piercing): Limpieza y protección del aplicador. f) Gestión de residuos.

B) Temario específico para tatuaje: Tendrá una duración de 15 horas teóricas y 5 prácticas con el siguiente contenido mínimo: a) Anatomía de la piel. b) Medidas preventivas; normas sanitarias. c) Higiene de los utensilios y utilización adecuada de los mismos (prácticas). d) Efectividad de las recomendaciones de cuidado y protección de los tatuajes. Cómo informar e implicar al cliente en el cuidado de su tatuaje.

C) Temario específico para perforación cutánea (piercing): Tendrá una duración de 20 horas con el siguiente contenido mínimo: a) Anatomía de la piel, las mucosas y zonas de posible perforación. b) Medidas preventivas. c) Higiene de los utensilios y uso adecuado (5 horas prácticas). d) Recomendaciones para dar la información sobre los cuidados de una perforación cutánea.

3. Test final: Evaluación final de los conocimientos adquiridos».

Vide Decreto 160/2002, de 30 de abril, del Departamento de Salud, Consumo y Servicios Sociales de Aragón, art. 6, donde incluye un programa similar al andaluz.

${ }^{47}$ Vide Decreto 286/2002, de 26 de noviembre, de la Consejería de Salud de la Junta de Andalucía, art. 6.3; Decreto 160/2002, de 30 de abril, del Departamento de Salud, Consumo y Servicios Sociales de Aragón, art. 8.4; Orden 17/2003, de 14 de marzo, de la Consejería de Sanidad y Consumo de Murcia, art. 4.5; Decreto 28/2001, de 23 de enero, del Departamento de Sanidad y Seguridad Social de la Generalitat de Catalunya, art. 6; Decreto 83/2002, de 23 de mayo, de la Consejería de Sanidad de la Generalitat Valenciana, art. 10. 
12. A utilizar las vías de reclamación y de propuesta de sugerencias en los plazos previstos. En uno u otro caso deberá recibir respuesta por escrito en los plazos que reglamentariamente se establezcan» ${ }^{48}$.

\section{AUTORIZACIÓN}

\section{Administrativa del centro}

Para el ejercicio de estas actividades será necesaria la obtención de la preceptiva autorización del Ayuntamiento o de las autoridades sanitarias ${ }^{49}$, previo cumplimiento de las condiciones que se determinen reglamentariamente. Esta autorización tendrá carácter previo al inicio de la actividad o a cualquier modificación sustancial o funcional del centro o establecimiento. Básicamente la documentación a aportar es la siguiente:

- Solicitud suscrita por el titular del establecimiento con sus datos personales, en la que se incluirá una descripción detallada de las instalaciones, del equipo e instrumental y de los métodos de esterilización y desinfección utilizados. Asimismo, deberán indicarse las técnicas de tatuaje y perforación cutánea que se aplican ${ }^{50}$.

\footnotetext{
${ }^{48}$ Vide Ley 2/1998, de 15 de junio, de Salud de Andalucía (art. 6.1.r)); Ley 6/2002, de 15 de abril, de Salud de Aragón (art. 4.1.h)); Ley 1/1992, de 2 de julio, de creación del Servicio de Salud del Principado (art. 49.12); Ley 5/2003, de 4 de abril, de Salud de las Islas Baleares (BOIB de 22 de abril, núm. 55), (art. 5.1e)); Ley 11/1994, de 26 de julio, de Ordenación Sanitaria de Canarias (art. 6.1.c)); Ley 8/2000, de 30 de noviembre, de Ordenación de la Sanidad de Castilla-La Mancha (art. 4.1.n)); Ley 8/2003, de 8 de abril, de Castilla y León, sobre derechos y deberes de las personas en relación con la Salud (art. 26.1)); Ley 10/2001, de 28 de junio, normas reguladoras de la salud en Extremadura (art. 11.1.ñ)); Ley Foral 10/1990, de 23 de noviembre, normas reguladoras de la salud en Navarra (art. 5.12); Ley 2/2002, de 17 de abril, de Salud de La Rioja (art. 13.5); Ley 1/2003, de 28 de enero, de derechos e información al paciente de la Comunidad Valenciana (art. 27).

${ }^{49} \mathrm{El}$ único supuesto en el que esta competencia se otorga a las autoridades sanitarias es el contemplado en la Orden 17/2003, de 14 de marzo, de la Consejería de Sanidad y Consumo de Murcia, art. 9.3: «Para la obtención de la autorización sanitaria de establecimiento de tatuaje o piercing, los interesados deberán cursar solicitud, por su representante legal, dirigida al Director General de Salud Pública, [...]». Vide Juan Francisco Pérez Gálvez, Creación y regulación de centros y establecimientos sanitarios, Bosch, Barcelona, 2003.

${ }^{50}$ Vide Decreto 286/2002, de 26 de noviembre, de la Consejería de Salud de la Junta de Andalucía, art. 14.1; Decreto 160/2002, de 30 de abril, del Departamento de Sanidad, Consumo y Servicios Sociales de Aragón, art. 8.3; Orden 17/2003, de 14 de marzo, de la Consejería de Sanidad y Consumo de Murcia, art. 9.3, a), b), c), d); Decreto 28/2001, de 23 de enero, del Departamento de Sanidad y Seguridad Social de la Generalitat de Catalunya, art. 14.1; Decreto 82/2002, de 23 de mayo, de la Consejería de Sanidad de la Generalitat Valenciana, art. 19.1a), b), c) y d).
} 
- Se deberá acreditar la formación del personal aplicador de estas técnicas ${ }^{51}$.

- Documentación que acredite la adquisición de material fungible y pigmentos ${ }^{52}$.

- Presentación del listado de residuos peligrosos que genera la actividad, y la acreditación de que se ha contratado la cesión de los mismos a un gestor autorizado por las respectivas Consejerías de Medio Ambiente ${ }^{53}$.

- Aquellos otros documentos que se consideren relevantes en virtud de las respectivas disposiciones autonómicas reguladoras de esta materia ${ }^{54}$.

La autorización concedida deberá constar de forma visible a los usuarios en el establecimiento ${ }^{55}$. Las Comunidades Autónomas podrán establecer un plazo de vigencia de dicha autorización, transcurrido el cual se producirá la caducidad de la misma que será declarada de oficio y se notificará al titular, procediendo este al cese de la actividad y cierre del establecimiento. Salvo que el titular con la antelación que se determine reglamentariamente, a la fecha de terminación de la vigencia, solicite la

\footnotetext{
${ }^{51}$ Vide Decreto 286/2002, de 26 de noviembre, de la Consejería de Salud de la Junta de Andalucía, art. 14.2; Decreto 160/2002, de 30 de abril, del Departamento de Sanidad, Consumo y Servicios Sociales de Aragón, art. 8.3; Decreto 28/2001, de 23 de enero, del Departamento de Sanidad y Seguridad Social de la Generalitat de Catalunya, art. 14.1; Decreto 82/2002, de 23 de mayo, de la Consejería de Sanidad de la Generalitat Valenciana, art. 19e).

${ }^{52}$ Vide Orden 17/2003, de 14 de marzo, de la Consejería de Sanidad y Consumo de Murcia, art. 9.3.h).

${ }^{53}$ Vide Decreto 286/2002, de 26 de noviembre, de la Consejería de Salud de la Junta de Andalucía, art. 14.3; Decreto 160/2002, de 30 de abril, del Departamento de Salud, Consumo y Servicios Sociales de Aragón, art. 7: «Los residuos cortantes o punzantes generados por la actividad desarrollada en los establecimientos de tatuaje, piercing o de ambos, tendrán el tratamiento de material de riesgo de transmisión de infecciones por lo que les será de aplicación la normativa vigente en cada momento en la Comunidad Autónoma de Aragón en materia de envasado y recogida de residuos sanitarios»; Orden 17/2003, de 14 de marzo, de la Consejería de Sanidad y Consumo de Murcia, arts. 7.7 y 9.3.e); Decreto 28/2001, de 23 de enero, del Departamento de Sanidad y Seguridad Social de la Generalitat de Catalunya, art. 12; Decreto Foral 132/2002, de 17 de junio, art. 5 .
}

${ }^{54}$ Vide Decreto 286/2002, de 26 de noviembre, de la Consejería de Salud de la Junta de Andalucía, art. 14.3; Orden 17/2003, de 14 de marzo, de la Consejería de Sanidad y Consumo de Murcia, art. 9.4; Decreto 28/2001, de 23 de enero, del Departamento de Sanidad y Seguridad Social de la Generalitat de Catalunya, art. 14.2.

55 Vide Orden 17/2003, de 14 de marzo, de la Consejería de Sanidad y Consumo de Murcia, art. 9.7 . 
renovación de la misma, aportando declaración expresa en la que manifieste que no han variado las condiciones existentes. Normalmente se determina que la autorización caducada no podrá ser objeto de rehabilitación, debiendo procederse, en su caso, a la obtención de una nueva ${ }^{56}$.

\section{Del usuario}

\subsection{Información y respeto de las decisiones adoptadas libre y voluntariamente por el usuario: una relación entre «iguales»}

Todo profesional está obligado no sólo a la correcta prestación de sus técnicas, sino al cumplimiento de los deberes de información y de documentación, y al respeto de las decisiones adoptadas libre y voluntariamente por el usuario ${ }^{57}$. Es decir, se trata de establecer una relación entre «iguales» ${ }^{58}$.

«Los derechos del paciente y del usuario de la sanidad pública son la clave para establecer relaciones entre iguales. Esta es una de las cosas que quiero significar de esta ley. Esto puede, si no acabar con ella, al menos amortiguar mucho esa relación de desconfianza o de desamparo que muchas veces tienen los pacientes o los usuarios $[\ldots] »$.

Evidentemente, estas referencias son aplicables en su totalidad a la materia que estoy estudiando.

\subsection{Derecho a la autonomía del usuario ${ }^{59}$ : consentimiento informado ${ }^{60}$, por representación, por escrito, condiciones de la información, renuncia a la misma y límites}

El estado de la legislación en el momento presente es el siguiente. El consentimiento:

\footnotetext{
56 Vide Orden 17/2003, de 14 de marzo, de la Consejería de Sanidad y Consumo de Murcia, art. 9.9, que establece un plazo de vigencia de la autorización de cinco años.

${ }^{57}$ Ley 41/2002, de 14 de noviembre, básica reguladora de la autonomía del paciente y de derechos y obligaciones en materia de información y documentación clínica (BOE de 15 de noviembre, núm. 274), art. 2.6.

${ }^{58}$ Vide Diario de Sesiones del Congreso de los Diputados, núm. 514, 12 de junio de 2002, dictamen, a la vista del informe elaborado por la ponencia, en relación con la proposición de ley sobre los derechos de información concernientes a la salud y la autonomía del paciente y la documentación clínica (Número de expediente 124/000002), p. 16.552, intervención de la señora Castro Fonseca, por el Grupo Parlamentario Federal de Izquierda Unida.

${ }^{59}$ Vide Ley 41/2002, de 14 de noviembre, básica reguladora de la autonomía del paciente y de derechos y obligaciones en materia de información y documentación clínica, art. 2. Principios
} 
«1. Toda actuación en el ámbito de la salud de un paciente necesita el consentimiento libre y voluntario del afectado, una vez que, recibida la información prevista en el artículo 4, haya valorado las opciones propias del caso.

2. El consentimiento será verbal por regla general. Sin embargo, se prestará por escrito en los casos siguientes: intervención quirúrgica, procedimientos diagnósticos y terapéuticos invasores $y$, en general, aplicación de procedimientos que suponen riesgos o inconvenientes de notoria y previsible repercusión negativa sobre la salud del paciente.

3. El consentimiento escrito del paciente será necesario para cada una de las actuaciones especificadas en el punto anterior de este artículo, dejando a salvo la posibilidad de incorporar anejos y otros datos de carácter general, y tendrá información suficiente sobre el procedimiento de aplicación y sobre sus riesgos.

4. Todo paciente o usuario tiene derecho a ser advertido sobre la posibilidad de utilizar los procedimientos de pronóstico, diagnóstico y terapéuticos que se le apli-

básicos: «2. Toda actuación en el ámbito de la sanidad requerirá con carácter general, el previo consentimiento de los pacientes o usuarios. El consentimiento que debe obtenerse después de que el paciente reciba una información adecuada, se hará por escrito en los supuestos previstos en la Ley.

3. El paciente o usuario tiene derecho a decidir libremente, después de recibir la información adecuada, entre las opciones clínicas disponibles».

${ }^{60}$ Vide Ley 41/2002, de 14 de noviembre, básica reguladora de la autonomía del paciente y de derechos y obligaciones en materia de información y documentación clínica, art. 3. Las definiciones legales: «Consentimiento informado: la conformidad libre, voluntaria y consciente de un paciente, manifestada en el pleno uso de sus facultades después de recibir la información adecuada, para que tenga lugar una actuación que afecta a su salud».

Vide STS de 12 de enero de 2001 (Ar. 3), F.D. 1. ${ }^{\circ}$ «[...]. Ciertamente que la iluminación y el esclarecimiento, a través de la información del médico para que el enfermo pueda escoger en libertad dentro de las opciones posibles que la ciencia médica le ofrece al respecto e incluso la de no someterse a ningún tratamiento, ni intervención, no supone un mero formalismo, sino que encuentra fundamento y apoyo en la misma Constitución Española, en la exaltación de la dignidad de la persona que se consagra en su artículo 10.1, pero sobre todo, en la libertad, de que se ocupan el art. 1.1 reconociendo la autonomía del individuo para elegir entre las diversas opciones vitales que se presenten de acuerdo con sus propios intereses y preferencias - sentencia del Tribunal Constitucional 132/1989, de 18 de junio- en el artículo 9.2, en el 10.1 y además en los Pactos Internacionales como la Declaración Universal de Derechos Humanos de 10 de diciembre de 1948, proclamada por la Asamblea General de las Naciones Unidad [...]. El consentimiento informado constituye un derecho humano fundamental, precisamente una de las últimas aportaciones realizadas en la teoría de los derechos humanos, consecuencia necesaria o explicación de los clásicos derechos a la vida, a la integridad física y a la libertad de conciencia. Derecho a la libertad personal, a decidir por sí mismo en lo atinente a la propia persona y a la propia vida y consecuencia de la autodisposición sobre el propio cuerpo».

Vide Manuel Alonso Olea, Las prestaciones del Sistema Nacional de Salud, Civitas, Madrid, 1999, pp. 131-136; Manuel Alonso OlEA, «El consentimiento informado en medicina y cirugía», $R A P, 155$, (2001), p. 25; Carlos María RoMEO CASABONA, «El consentimiento informado en la relación entre el médico y el paciente: Aspectos jurídicos», Problemas prácticos del consentimiento informado, Fundación Víctor Grífols i Lucas, 5, (2002), pp. 63-133. 
quen en un proyecto docente o de investigación, que en ningún caso podrá comportar riesgo adicional para su salud.

5. El paciente puede revocar libremente por escrito su consentimiento en cualquier momento» 6162 .

\section{Consentimiento por representación:}

«[...]. 3. Se otorgará el consentimiento por representación en los siguientes supuestos:

a) Cuando el paciente no sea capaz de tomar decisiones, a criterio del médico responsable de la asistencia o su estado físico o psíquico no le permita hacerse cargo de su situación. Si el paciente carece de representante legal, el consentimiento lo prestarán las personas vinculadas a él por razones familiares o de hecho.

b) Cuando el paciente esté incapacitado legalmente.

${ }^{61}$ Ley 41/2002, de 14 de noviembre, básica reguladora de la autonomía del paciente y de derechos y obligaciones en materia de información y documentación clínica, art. 8.

${ }^{62}$ Vide Ley 6/2002, de 15 de abril, de Salud de Aragón, art. 12.

«1. Cualquier intervención que se produzca en el ámbito de la salud requiere el consentimiento específico y libre de la persona afectada, tras haber sido informada conforme a lo establecido en el artículo 8 de esta Ley. El consentimiento debe realizarse por escrito en los casos de intervenciones quirúrgicas, procedimientos diagnósticos invasivos $y$, en general, cuando se lleven a cabo procedimientos que puedan suponer riesgos e inconvenientes notorios y previsibles susceptibles de repercutir en la salud del paciente.

2. Se efectuará un documento de consentimiento para cada supuesto, sin perjuicio de que se puedan adjuntar hojas y otros medios informativos de carácter general. El documento deberá contener como mínimo información sobre la finalidad y naturaleza de la intervención, así como sus riesgos y consecuencias más frecuentes.

3 . En el caso de que el paciente manifieste su voluntad de no ser informado, sin perjuicio de obtenerse el consentimiento previo para la intervención, deberá dejarse constancia documentada de esta renuncia en la historia clínica.

4. En cualquier momento la persona afectada puede revocar libremente su consentimiento.

5. En todos los casos en que el paciente haya expresado por escrito su consentimiento informado, tendrá derecho a que se le dé una copia del documento firmado». En el art. 13 se recogen las excepciones a la exigencia del consentimiento y en el art. 14 el otorgamiento del consentimiento por sustitución».

Vide Ley 7/2002, de 10 de diciembre, de Ordenación Sanitaria de Cantabria, art. 30; Ley 21/2000, de 29 de diciembre, de Cataluña, sobre derechos de información concerniente a la salud, a la autonomía del paciente y a la documentación clínica, arts. 6 y 7; Ley 3/2001, de 28 de mayo, de Galicia, normas reguladoras del consentimiento informado y de la historia clínica de los pacientes, Título II, arts. 3-12; Ley Foral 11/2002, de 6 de mayo, sobre los derechos del paciente a las voluntades anticipadas, a la información y a la documentación clínica, arts. 7 y 8; Ley 2/2002, de 17 de abril, de Salud de La Rioja, arts. 6.1, 2, 3, 4 y 7.6; Ley 1/2003, de 28 de enero, de derechos e información al paciente de la Comunidad Valenciana, art. 8. 
c) Cuando el paciente menor de edad no sea capaz intelectual ni emocionalmente de comprender el alcance de la intervención. En este caso, el consentimiento lo dará el representante legal del menor después de haber escuchado su opinión si tiene doce años cumplidos. Cuando se trate de menores no incapaces ni incapacitados, pero emancipados o con dieciséis años cumplidos, no cabe prestar el consentimiento por representación. Sin embargo, en caso de actuación de grave riesgo, según el criterio del facultativo, los padres serán informados y su opinión será tenida en cuenta para la toma de la decisión correspondiente. [...].

5. La prestación del consentimiento por representación será adecuada a las circunstancias y proporcionada a las necesidades que haya que atender, siempre en favor del paciente y con respeto a su dignidad personal. El paciente participará en la medida de lo posible en la toma de decisiones a lo largo del proceso sanitario» ${ }^{63}$.

\section{Información que se debe proporcionar:}

«1. El facultativo proporcionará al paciente, antes de recabar su consentimiento escrito, la información básica siguiente:

a) Las consecuencias relevantes o de importancia que la intervención origina con seguridad.

b) Los riesgos relacionados con las circunstancias personales o profesionales del paciente.

c) Los riesgos probables en condiciones normales, conforme a la experiencia y al estado de la ciencia o directamente relacionados con el tipo de intervención.

d) Las contraindicaciones.

2. El médico responsable ${ }^{64}$ deberá ponderar en cada caso que cuanto más dudoso sea el resultado de una intervención más necesario resulta el previo consentimiento por escrito del paciente» 6566 .

${ }^{63}$ Ley 41/2002, de 14 de noviembre, básica y reguladora de la autonomía del paciente y de derechos y obligaciones en materia de información y documentación clínica, art. 9. Vide Ley 7/2002, de 10 de diciembre, de Ordenación Sanitaria de Cantabria, arts. 31 y 32; Ley 1/2003, de 28 de enero, de derechos e información al paciente de la Comunidad Valenciana, art. 9.

${ }^{64}$ Vide Ley 41/2002, de 14 de noviembre, básica y reguladora de la autonomía del paciente y de derechos y obligaciones en materia de información y documentación clínica, art. 3. Las definiciones legales: «Médico responsable: el profesional que tiene a su cargo coordinar la información y la asistencia sanitaria del paciente o del usuario, con el carácter de interlocutor principal del mismo en todo lo referente a su atención e información durante el proceso asistencial, sin perjuicio de las obligaciones de otros profesionales que participan en las actuaciones asistenciales».

${ }^{65}$ Ley 41/2002, de 14 de noviembre, básica y reguladora de la autonomía del paciente y de derechos y obligaciones en materia de información y documentación clínica, art. 10.

${ }^{66}$ Vide José Manuel Martín BernaL, Responsabilidad médica y derechos de los pacientes, La Ley, Madrid, 1998, pp. 334-340: «El consentimiento informado y la enfermería». En las pp. 339 y 340 expone los artículos del Código Deontológico de la Enfermería Española referentes al consentimiento informado en la práctica asistencial de este colectivo profesional: 


\title{
La renuncia a recibir información:
}

«1. La renuncia del paciente a recibir información está limitada por el interés de la salud del propio paciente, de terceros, de la colectividad y por las exigencias terapéuticas del caso. Cuando el paciente manifieste expresamente su deseo de no ser informado, se respetará su voluntad haciendo constar su renuncia documentalmente, sin perjuicio de la obtención de su consentimiento previo para la intervención» ${ }^{67} 68$.

\subsection{Su aplicación a la práctica del tatuaje y piercing}

\author{
El personal aplicador, previamente a la utilización de estas técnicas \\ deberá informar al usuario, de manera comprensible y por escrito, de todos
}

«Artículo 7. El consentimiento del paciente, en el ejercicio libre de la profesión, ha de ser obtenido siempre, con carácter previo, ante cualquier intervención de la enfermera/o. Y lo harán en reconocimiento del derecho moral que cada persona tiene a participar de forma libre y válidamente manifestada sobre la atención que se le preste.

Artículo 8. Cuando el enfermo no esté en condiciones físicas y psíquicas de prestar su consentimiento, la enfermera/o tendrá que buscarlo a través de los familiares o allegados a éste.

Artículo 9. La enfermera/o nunca empleará, ni consentirá que otros lo empleen, medidas de fuerza física o moral para obtener el consentimiento del paciente. En caso de ocurrir así, deberá ponerlo en conocimiento de las autoridades sanitarias y del Colegio Profesional respectivo con la mayor urgencia posible». Vide Redacción, «La falta de consentimiento no genera responsabilidad si no hay daño», Diario Médico, 5 de julio de 2002, pp. 1 y 7, donde se indica (p. 1): «Si no hay daño, la omisión del consentimiento informado no genera ningún tipo de responsabilidad censurable judicialmente, según ha declarado el Tribunal Superior de Justicia de Navarra. El fallo absuelve a un médico por no existir daño asociado al acto médico y por considerar que sólo la falta de consentimiento no conlleva responsabilidad». Vide Juan PemÁn Gavín, «Hacia un estatuto del enfermo hospitalizado», RAP , 103, (1984), pp. 116-124: «El consentimiento del paciente a las prestaciones diagnósticas y curativas». Vide Juan José GonzÁlez RIVAS, «Últimos criterios jurisprudenciales sobre responsabilidad patrimonial de la Administración sanitaria», VII Congreso Nacional de Derecho Sanitario, Fundación Mapfre Medicina, Madrid, 2001, pp. 180-182, donde estudia la «Incidencia del consentimiento informado en el ámbito de la sanidad».

${ }^{67}$ Ley 41/2002, de 14 de noviembre, básica y reguladora de la autonomía del paciente y de derechos y obligaciones en materia de información y documentación clínica, art. 9.

${ }^{68}$ Vide Ley 2/1998, de 15 de junio, de Salud de Andalucía (art. 6.1.ñ); Ley 6/2002, de 15 de abril, de Salud de Aragón (art. 4.1.f)); Ley 1/1992, de 2 de julio, de creación del Servicio de Salud del Principado (art. 49.6); Ley 5/2003, de 4 de abril, de Salud de las Islas Baleares (art. 11.1); Ley 11/1994, de 26 de julio, de Ordenación Sanitaria de Canarias (art. 6.1.o)); Ley 7/2002, de 10 de diciembre, de Ordenación Sanitaria de Cantabria, art. 33; Ley 8/2000, de 30 de noviembre, de Ordenación de la Sanidad de Castilla-La Mancha (art. 4.1.k)); Ley 8/2003, de 8 de abril, de Castilla y León, sobre derechos y deberes de las personas en relación con la salud (art. 19)); Ley 10/2001, de 28 de junio, normas reguladoras de la salud en Extremadura (art. 11.1.h)); Ley Foral 10/1990, de 23 de noviembre, normas reguladoras de salud en Navarra (art. 5.6); Ley Foral $11 / 2002$, de 6 de mayo, sobre los derechos del paciente a las voluntades anticipadas, a la información y a la documentación clínica (art. 6); Ley 2/2002, de 17 de abril, de Salud de La Rioja (art. 9.1); Ley $1 / 2003$, de 28 de enero, de derechos e información al paciente de la Comunidad Valenciana (arts 10-12). 
los pormenores de estas prácticas, recabando su firma en el mismo documento por el que se le informa. Deberá negarse a realizar la aplicación si considera que el usuario no está en condiciones físicas o psíquicas de tomar una decisión adecuada, o de llevar a cabo las tareas de limpieza y cuidados posteriores, o si considera insuficiente cualquier otro aspecto que resulte relevante para la salud del usuario o la del propio personal aplicador ${ }^{69}$. Es decir, deberán aplicar en su totalidad las disposiciones legales vigentes en esta materia, que han sido expuestas en el apartado anterior, incluyendo el consentimiento por escrito de los representantes legales de los menores de edad o incapacitados.

\section{CONTROL E INSPECCIÓN}

\section{Una consideración preliminar}

\subsection{El concepto de control}

Los mecanismos de control son diversos. Pensemos por ejemplo en el control desempeñado por las instituciones de policía o vigilancia pública, o en el control ejercido por los registros públicos. Sin embargo, quizás el más genuino sea el de la inspección como medio de control, que tiene evidentes peculiaridades respecto del control que se acomete a través de otros medios. A juicio de Ramón PARADA, el control es la actividad que permite comprobar la adecuación de la Administración a las normas y fines establecidos en el ordenamiento jurídico. En ese empeño están responsabilizados todos los poderes del Estado ${ }^{70}$. Asimismo distingue: control de legalidad, control de oportunidad, control de eficacia, control sucesivo, control permanente que supone la vigilancia continua y controles provocados.

\footnotetext{
${ }^{69}$ Vide Decreto 286/2002, de 26 de noviembre, de la Consejería de Salud de la Junta de Andalucía, art. 9; Orden 17/2003, de 14 de marzo, de la Consejería de Sanidad y Consumo de Murcia, arts. 4.2 y 4.3; Decreto Foral 132/2002, de 17 de junio, arts. 7.3 y 7.4 (en el primero de los artículos citados determina que los titulares de los establecimientos deberán mantener un registro actualizado de clientes, y que este registro se mantendrá en el establecimiento al menos durante un año); Decreto 83/2002, de 23 de mayo, de la Consejería de Sanidad de la Generalitat Valenciana, arts. 8 (donde incluye la referencia al registro de clientes), 16: «Los profesionales dedicados a las prácticas objeto de la presente reglamentación deberán contar y poner a disposición del cliente protocolos de preparación de la zona anatómica donde se realizará el tatuaje o piercing, así como sobre procedimientos de los cuidados posteriores. Deberá quedar constancia escrita de que el usuario ha recibido dicha información y que da su consentimiento» y 18 (Protección del menor).

70 Vide Ramón Parada Vázquez, Derecho Administrativo, Vol. II, Marcial Pons, Madrid, 1997, pp. 62-64.
} 
La actividad de control implica la situación de supremacía en la que se encuentra el órgano que controla respecto del controlado. Se materializa en unos mecanismos de contacto, de vínculos, de la Administración con la realidad en la que aquella adopta una conducta activa de comprobación de la adecuación del ser al deber ser. Culmina en la formulación de una declaración de juicio sobre las concordancias o discordancias entre los comportamientos de los órganos y personas y la previsión que de los mismos se hace por el legislador. Y todo ello implica que la actividad de control es el presupuesto jurídico de otra actividad, que es la que tiende a determinar las reacciones que las discordancias constatadas entre realidad y modelo legislativo producen.

Se configura como una técnica dual. Por una parte, es utilizado como un método de organización por parte de la Administración. Es decir, se pretende verificar si ciertas conductas se adecuan o no a los fines previamente establecidos. Por otra, la actividad administrativa de control se efectúa en el entorno del cumplimiento de los deberes enmarcados en las normas jurídico-públicas. Verificar si existe la exigida adecuación a lo debido 71. Dado que el acto de inspección se dirige a comprobar el respeto de los preceptos, con el fin de tutelar intereses generales o particulares, y por tanto se orienta no sólo al fin de adquirir noticias, sino a ejercer un control, la relación entre éste y la inspección vendría a ser una relación de género y especie, con las consecuencias que tal aseveración implica. Por tanto, entre las distintas finalidades de la técnica de control puedo citar las siguientes: verificar el cumplimiento de deberes que tiene el ciudadano, cuya incidencia sobre terceros lo es sólo de manera mediata; en otras ocasiones el control se extiende al cumplimiento de la normativa que implica protección de terceros e incluso la protección frente a uno mismo (normas de edificación, seguridad vial, etc.); en ocasiones se orienta al control de las normas que tutelan determinados intereses públicos o generales, más que de la propia Administración (patrimonio histórico, urbanismo, etc.); o se utiliza para el control de determinadas normas jurídico-privadas, pero que tienen una especial incidencia sobre la protección de los ciudadanos generalmente frente a empresas, ante las que se encuentran en situación objetiva de inferioridad (control sanitario de centros, servicios o establecimientos) ${ }^{72}$.

\footnotetext{
${ }^{71}$ Vide J. Amenos Álamo, La inspección urbanística: concepto y régimen jurídico, Cedecs, Barcelona, 1999, p. 54, donde alude a la etimología del término «control», que viene de la voz francesa contro-rôle, cuyas raíces vienen a su vez del latín rotulus, esto es, el folio en el que se diseña un esquema un plano con el que debe coincidir la realidad.

72 Vide Eduardo González Biedma, La inspección de trabajo y el control de la aplicación de la norma laboral, Aranzadi, Pamplona, 1999, p. 42.
} 


\subsection{El concepto de inspección}

No es fácil precisar el contenido de la función de inspección de modo general y abstracto. Ni las normas sobre la misma, ni el sentido usual de la expresión (que remite a las ideas de acción de vigilar, examinar minuciosamente, reconocer, controlar o comprobar) aportan perfiles claros ${ }^{73}$.

El término inspección, como el de otras categorías del Derecho administrativo, puede tener distintas acepciones. Una puede tener carácter objetivo, y por tanto se referirá a la función o actividad. Otra puede tener carácter subjetivo, y se referirá a los órganos administrativos que tienen encomendada dicha función. Pero en ocasiones las cosas no son tan claras como parecen, porque con frecuencia se encomiendan a la inspección funciones adicionales a su propia actividad, o se ejerce esta función por órganos no especializados exclusivamente en ella. Por todo ello me parece necesario intentar formular un concepto sobre esta actividad.

Se puede definir la actividad de inspección ${ }^{74}$ del siguiente modo:

«Se habla de actividad, función o potestad de inspección, sin excesiva precisión en este momento, para identificar unas actuaciones más o menos genéricamente previstas en el ordenamiento jurídico, que habilitan a las Administraciones públicas para llevar a cabo funciones de comprobación o constatación del cumplimiento de la normativa vigente, en su sentido más amplio, esto es, incluidas muy especialmente las condiciones y requisitos de orden técnico, consecuencia inherente de la imposición que a determinadas personas, actividades, instalaciones, objetos y productos hacen ciertas normas jurídicas. El motivo principal de la dotación y ejercicio de estas funciones de inspección y control es, en cualquier plano, la seguridad» ${ }^{75}$.

Puedo afirmar que la actividad de inspección es una potestad de la Administración ${ }^{76}$ que ejercita una actividad administrativa de policía mediante funcionarios, a través del procedimiento administrativo, para comprobar o constatar el cumplimiento de la normativa sanitaria o realizar cuantas actuaciones sean precisas, en orden al cumplimiento de sus fun-

\footnotetext{
${ }^{73}$ Vide Manuel Rebollo PuIG, «La organización de la inspección de consumo», en La inspección de consumo en el contexto de la actuación administrativa, Gobierno Vasco, Vitoria, 1992, p. 21.

${ }^{74}$ Sobre la definición o concepto histórico de la voz «Inspector», vide Ricardo RIVERo OrTEGA, El Estado vigilante, Tecnos, Madrid, 2000, pp. 38-39.

${ }^{75}$ Vide José BermeJo VerA, «La Administración inspectora», RAP, 147, (1998), pp. 40-41.

${ }^{76}$ Vide STS de 20 de octubre de 1994 (Ar. 8086), F.D. 3..$^{\circ}$ : «La potestad administrativa es un poder jurídico reconocido por el ordenamiento jurídico y su ejercicio exige que se concreten determinadas circunstancias fácticas determinantes del ejercicio de la potestad en el plano de la legalidad aplicable. Todo ejercicio de potestad por parte de la Administración, genera una situación jurídica con el administrado, en la que aquella — la Administración — ocupa la situación de sujeto activo: esa relación jurídica está regulada por el Derecho Administrativo».
} 
ciones, recabando si es necesario el auxilio de las restantes Administraciones y de los ciudadanos, con carácter instrumental, externo, técnico, inmediato, reglado y maximalista ${ }^{77}$. Por todo ello se alude a una función pública y a un particular procedimiento reglado de comprobación llevado a cabo por determinados agentes de la Administración, de modo que el que inspecciona no sólo investiga, constata, da fe de alguna circunstancia, sino que, además, lo hace con un concreto fin, como es contrastar la adecuación de lo observado a lo que es debido, y que es sobradamente conocida por los ciudadanos ${ }^{78}$.

Por todo ello, la diferencia fundamental entre la inspección y las demás facultades se circunscriben al desarrollo efectivo de la actividad de que se trate, mientras que la inspección encuentra su cometido en el objeto. Dicho de otro modo, tienen por misión el control del riesgo derivado preferentemente de actuaciones u omisiones directas de personas físicas, mientras que la actividad de inspección tiene por objeto el control de los riesgos concretos o abstractos, inmediatos o hipotéticos, derivados de la titularidad de una actividad organizada, típicamente en un establecimiento o instalación ${ }^{79}$.

\footnotetext{
77 Vide Severiano FeRnÁNDEZ RAMOS, «La inspección en el marco del control de la aplicación del derecho ambiental», Revista de Derecho Ambiental, 24, (2000), p. 19, donde formula un concepto de acción inspectora en materia ambiental: «En el Derecho interno español, desde el punto de vista competencial, la acción inspectora en materia ambiental, como en cualquier otra materia, consiste en un aspecto de la actividad de ejecución de la legalidad ambiental, pues tiene por objeto primordial la protección de la legalidad, mediante la vigilancia y fiscalización de su cumplimiento por parte de los sujetos obligados. Se trata, por tanto, de una competencia de disciplina o policía administrativa. Más concretamente, aun cuando la actividad inspectora puede servir para el ejercicio de varias potestades de policía administrativa, como la autorizatoria, lo cierto es que se trata de una función pública instrumentalmente ligada al ejercicio de una potestad sancionadora, puesto que debe entenderse que la atribución de esta potestad comporta la de aquellos medios e instrumentos imprescindibles para su ejercicio y efectividad, de modo que otra instancia pública no condicione su desarrollo».
}

78 Vide Eduardo González Biedma, La inspección de trabajo y el control de la aplicación de la norma laboral, Aranzadi, Pamplona, 1999, p. 38. Vide Sentencia del Tribunal Superior de Justicia de Madrid (Ar. 370), F.D. Único: «[...], si lo hace sin acudir siquiera a la Inspección de los Servicios Sanitarios del Insalud para informar de que uno de sus médicos se negaba a operarle y otro le ofrecía hacerlo como privado, es evidente que no puede hablarse de denegación de asistencia ni, desde luego, cabe hablar de compensación de culpas en el sentido de que existió una doble falta: la del actor por no acudir a la inspección y la de los servicios sanitarios que — se dice en la resolución recurrida - debieron haber reconducido al actor a fin de hacer posible su intervención por el médico que la llevó a cabo posiblemente en el marco de las instituciones de la Seguridad Social, pues la existencia de la inspección es sobradamente conocida por cualquier beneficiario de la Seguridad Social y es natural la desconfianza que debe despertar el que un médico de la Seguridad Social, y a un paciente de ésta, le ofrezca intervención a realizar por él mismo en la medicina privada, lo que debió ponerse en conocimiento de dicha inspección, [...]».

79 Vide STC 113/1983, de 6 de diciembre (Conflicto positivo de competencia núm. 295/1982), F.J.2. ${ }^{\circ}$, que declara la competencia estatal de vigilancia de costas, pero no incluye la inspección y 


\section{Cometido asignado en este tipo de establecimientos}

De conformidad con lo preceptuado en el artículo 42 de la Ley General de Sanidad y en las respectivas leyes de salud de las Comunidades Autónomas, el control e inspección de lo establecido en las distintas disposiciones reglamentarias reguladoras de esta materia, corresponderá a los municipios, que podrán recabar el apoyo técnico del personal y medios de las áreas de salud en cuya demarcación estén comprendidos ${ }^{80}$. En todo caso parece razonable entender que la Administración autonómica competente en materia sanitaria tiene libre acceso a todas las dependencias de los establecimientos de tatuaje y/o piercing con la finalidad de comprobar el cumplimiento de las prescripciones legales y reglamentarias ${ }^{81}$. Es más, la Comunidad de Murcia establece de modo claro y taxativo, que presentada toda la documentación y previa a la resolución de autorización, se procederá a realizar visita de inspección en la que se comprobará la idoneidad y el cumplimiento de la normativa que le es de aplicación. Dado que corresponde autorizar en esta Comunidad al Director General de Salud Pública, y que la solicitud de autorización también se presentó inicialmente ante el mismo, cabe suponer, que será la inspección sanitaria de la Consejería la que efectúe la preceptiva visita y el pertinente acta de inspección. Sin embargo la redacción de la propia Orden reguladora de esta materia, es confusa y contradictoria ${ }^{82}$.

sanción de las actividades de pesca, pues el control de los barcos de pesca con fines de defensa y seguridad nacional no implica la inspección técnica de la actividad económica.

${ }^{80}$ Vide Decreto 286/2002, de 26 de noviembre, de la Consejería de Salud de la Junta de Andalucía, art. 15; Decreto 160/2002, de 30 de abril, del Departamento de Salud, Consumo y Servicios Sociales de Aragón, art. 8.2; Orden de 14 de enero de 2003, del Departamento de Salud, Consumo y Servicios Sociales de Aragón (BOE de 29 de enero de 2003, núm. 11), que desarrolla el Decreto 160/2002, de 30 de abril, que aprueba el Reglamento por el que se regulan las normas sanitarias aplicables a los establecimientos de tatuaje o piercing, donde determina: «Segundo. [...] corresponde al Ayuntamiento respectivo dictar la Resolución de autorización de apertura. Tercero. Los Ayuntamientos que tengan ubicados en su ámbito territorial establecimientos de tatuaje o piercing, realizarán las inspecciones periódicas de dichos establecimientos, sin perjuicio de que la Administración Autonómica sanitaria pueda inspeccionar en todo momento dichos establecimientos». Vide Decreto 28/2001, de 23 de enero, del Departamento de Sanidad y Seguridad Social de la Generalitat de Catalunya, art. 15.

${ }^{81}$ Vide Decreto 160/2002, de 30 de abril, del Departamento de Salud, Consumo y Servicios Sociales de Aragón, art. 9.

82 Vide Orden 17/2003, de 14 de marzo, de la Consejería de Sanidad y Consumo de Murcia, art. 9.6. En el art. 10 establece: «1. En el ejercicio de sus competencias, los Ayuntamientos inspeccionarán los lugares en los que se realicen actividades de tatuaje o «piercing» y acordarán, de forma cautelar, las medidas de policía sanitaria que, en defensa de la salud pública, les atribuye la legislación vigente. 2. A efectos de verificar el cumplimiento de este Decreto, la Consejería de Sanidad y Consumo, a través de sus correspondientes servicios técnicos, realizará las actuaciones inspec- 
En todo caso se suele citar en las disposiciones autonómicas reguladoras de esta materia el «autocontrol continuado» por parte de los responsables de los establecimientos, como baluarte del cumplimiento de estas disposiciones ${ }^{83}$. Lo que no deja de ser una paradoja.

\section{RÉGIMEN SANCIONADOR}

\section{Infracciones y sanciones ${ }^{84}$ : Remisión al régimen sancionador de la Ley General de Sanidad}

Una primera aproximación doctrinal a esta materia me lleva a citar como obra de referencia, ese magnífico libro del profesor Alejandro NiETo: Derecho administrativo sancionador ${ }^{85}$, una obra que tardará mucho tiempo en ser superada, si es que llega a serlo. A continuación debo manifestar que el incumplimiento de los requisitos podrá dar lugar, previa instrucción del expediente oportuno, a la aplicación del régimen de infracciones y sanciones establecido en el capítulo VI del título I de la Ley 14/1986, de 25 de abril, General de Sanidad ${ }^{86}$. Así lo han establecido las Comunida-

toras y controles necesarios tanto en los establecimientos de tatuaje o «piercing», como en instalaciones no estables donde se desarrollen estas actividades». Confusión que se acrecienta, pues los órganos competentes para imponer las sanciones son: el Director General de Salud Pública, el Consejero de Sanidad y Consumo y el Consejo de Gobierno (art. 11.3), es decir, el Alcalde carece de competencia alguna sobre el particular. Vide Decreto 83/2002, de 23 de mayo, de la Consejería de Sanidad de la Generalitat Valenciana, art. 19.3.

${ }^{83}$ Vide Decreto 160/2002, de 30 de abril, del Departamento de Salud, Consumo y Servicios Sociales de Aragón, por el que se establecen las normas sanitarias aplicables a los establecimientos de tatuaje (BOA de 20 de mayo), Justificación de la disposición; Orden 17/2003, de 14 de marzo, de la Consejería de Sanidad y Consumo de Murcia, art. 4.3; Decreto 28/2001, de 23 de enero, del Departamento de Sanidad y Seguridad Social de la Generalitat de Catalunya, Justificación de la disposición (DOGC de 1 de febrero, núm. 3318) y arts. 9 y 10; Decreto Foral 132/2002, de 17 de junio, art. 7.

${ }^{84}$ Vide J. SuAy Rincón, Sanciones administrativas, Publicaciones del Real Colegio de España, Bolonia, 1989, pp. 55 y 56, donde distingue cinco elementos en las sanciones administrativas: «1) El carácter administrativo de la autoridad de la que emanan (elemento subjetivo); 2) El efecto aflictivo de la medida en que se exteriorizan (elemento objetivo); 3) La realización de una conducta contraria a Derecho, con carácter previo; 4) La finalidad represora que persigue (elemento teleológico); 5) El carácter administrativo del procedimiento que ha de observarse».

85 Vide Alejandro NiETo, Derecho administrativo sancionador, Tecnos, Madrid, 1994, in toto. Cualquier análisis o estudio debe partir de este trabajo.

${ }^{86}$ Vide Ley 41/2002, de 14 de noviembre, básica reguladora de la autonomía del paciente y de derechos y obligaciones en materia de información y documentación sanitaria, Disposición adicional sexta: «Régimen sancionador. Las infracciones de lo dispuesto por la presente Ley quedan sometidas al régimen sancionador previsto en el capítulo VI del Título I de la Ley 14/1986, General de Sanidad, sin perjuicio de la responsabilidad civil o penal y de la responsabilidad profesional o estatutaria procedentes en derecho». 
des Autónomas con carácter general, aunque de modo complementario suelen tipificar infracciones y sanciones en el marco de las Leyes reguladoras de salud o disposiciones reglamentarias que las desarrollan, en sus respectivos ámbitos competenciales ${ }^{87}$.

Sin embargo, la remisión general a la LGS, no está exenta de críticas, tal y como se pone de manifiesto en el Diario de Sesiones del Congreso de los Diputados, núm. 514, en la celebrada el 12 de junio de 2002, por la señora Uría Etxebarría en representación del Grupo Parlamentario Vasco, p. 16.550-16.551, en relación con la Ley 41/2002, de 14 de noviembre (BOE de 15 de noviembre, núm. 274):

«Hay una objeción importantísima, que la he manifestado ya a algunos ponentes de la ley y que nos parece que es obligado que la corrijamos en el Senado, la que hace referencia a la disposición adicional quinta. Nos parece que es perfectamente incorrecta desde el punto de vista técnico, que es inoportuna y que puede convertir en ineficaz incluso la propia pretensión de la norma, por dos razones fundamentales. Primero, porque al establecer el régimen sancionador o el régimen disciplinario en relación con la norma es contraproducente que se haga por la mera referencia a una ley que lo es de 1986, es contraproducente, repito, para la seguridad jurídica y peligrosa desde el punto de vista del principio de legalidad. Para que no se desborden los límites marcados por la garantía material del principio de legalidad, que es garantía constitucional —está en el artículo 25 de la Constitución, en el núcleo duro de la Constitución-, debe interpretarse que sólo serán infracciones las conductas que vulneren los preceptos de la ley y que sean subsumibles entonces en los tipos descritos

${ }^{87}$ Vide Ley 2/1998, de 15 de junio, de Salud de Andalucía (art. 25.a) y c)); Ley 6/2001, de 15 de abril, de Salud de Aragón (art. 41.b) y c)); Decreto 42/1994, de 16 de junio, de Asturias, por el que se regula el procedimiento de autorización para la creación, modificación y supresión o cierre de centros y establecimientos sanitarios (art. 9.1); Ley 5/2003, de 4 de abril, de Salud de las Islas Baleares (arts. 54-63). Vide Decreto 163/1996, de 26 de julio, de las Islas Baleares, que regula la autorización para la creación, modificación, traslado y cierre de centros, establecimientos y servicios sanitarios (art. 14)]; Ley 11/1994, de 26 de julio, de Ordenación sanitaria de Canarias (art. 37.b), c), d), f), g), h), i), j)); Ley 8/2000, de 30 de noviembre, de Ordenación de la Sanidad de Castilla-La Mancha (arts: 37. a), b) c), d), e), f), g), h); 38.a), b), c), d), e), f), i), j), k), 1); 39.a), b), c), f), g), h), i), j), k), 1)); Ley 1/1993, de 6 de abril, de Ordenación del Sistema Sanitario de Castilla y León [(art. 36.2.a), b), c), e)). Vide Decreto 93/1999, de 29 de abril, que determina el régimen jurídico y procedimiento para la autorización y creación del registro de centros, servicios y establecimientos sanitarios y sociosanitarios, art. 18.1]; Decreto 77/2001, de 29 de marzo, de Galicia, que regula los centros, servicios y establecimientos (art. 6.1); Ley 12/2001, de 21 de diciembre, de la Asamblea de Madrid, de ordenación de la sanidad, art. 144.3.a) y b); Decreto 110/1997, de 11 de septiembre, de Madrid, por el que se regula el régimen jurídico de las autorizaciones de centros, servicios y establecimientos sanitarios, art. 11.1; Ley 10/2001, de 28 de junio, de Extremadura, normas reguladoras de la salud (arts: 52.3.a). 1, 2 y 3; 52.3.b). 1, 2, 3, 4, 5, 6, 7, 8, 9, 11, 12 y 17; 52.3.c). 4, 5 y 7); Ley 4/1989, de 26 de julio, de Murcia, normas reguladoras de sanidad (art. 4); Ley Foral 10/1990, de 23 de noviembre, de Navarra, normas reguladoras de salud (art. 27.2.a), c), e)); Ley 2/2002, de 17 de abril, de Salud de La Rioja, de salud (arts: 111.2.a); 111.3.b), c), d), e), 1), m), n)); Decreto 396/1994, de 11 de octubre, del País Vasco, por el que se regula la apertura, funcionamiento y modificación de centros, servicios y establecimientos sanitarios (art. 12). 
en la Ley 14/1986, y esto aboca a una tarea aplicativa de alto riesgo en la extensión de los tipos. Además, se supone que de 1986 a aquí, algún contenido nuevo, algo innovador, habremos pretendido con esta norma, y todo eso quedaría ayuno de la posibilidad de subsumirlo en los tipos previstos en una ley de hace tiempo. En efecto, al no describirse las conductas específicas, que es lo que creo absolutamente imprescindible hacer, que lesionen o pongan en peligro los concretos fines jurídicos a que la regulación que vamos a aprobar atiende, el aplicador tenderá a forzar los tipos de la ley de 1986 para cubrir todas las conductas que conlleven tales consecuencias. Se puede decir que la omisión del legislador, nuestra omisión, en lo tocante a la descripción de los tipos específicos coherentes con las peculiaridades reguladoras de la ley, traslada entonces a la Administración la responsabilidad de detectar las conductas que afecten a los bienes y valores jurídicos especialmente contemplados en la ley y aplicar a los mismos los tipos de una ley del año 1986, por lo que ello conlleva el riesgo de interpretaciones analógicas y extensivas, contrarias al principio de legalidad sancionadora y respecto del cual hay abundantísima jurisprudencia constitucional.

Hay una segunda razón. Limita mucha la eficacia de la regulación legal. Si pretendemos que esta norma sea aplicable, tenemos que establecer un régimen sancionador que efectivamente tenga las virtualidades de disuasión que toda norma pretende. Gran parte de esta eficacia — de la eficacia de la norma- depende de la adecuación del régimen sancionador, es decir, de su capacidad de evitar a través de la prevención las conductas u omisiones que más gravemente lesionen o pongan en peligro los bienes jurídicos — bienes jurídicos trascendentales - que esta ley pretende proteger. Es evidente que para lograr esa adecuación se requiere un esfuerzo para detectar esas conductas y describirlas con precisión en los tipos de infracción y por fijar las sanciones que les corresponde proporcionalmente con la gravedad de estas conductas, cosa que obviamente no se hace en las disposiciones que analizamos.

La remisión que tal disposición realiza traslada, como hemos visto, a la Administración la responsabilidad de conseguir una respuesta sancionadora adecuada a las necesidades de protección de los bienes jurídicos a los que la ley atiende, y esta traslación conlleva una clarísima ineficacia al respecto, pues la Administración no puede crear nuevos tipos ni aumentar las sanciones ni extender o aplicar analógicamente los ya establecidos y en muchas ocasiones supondrá dejar sin sancionar conductas específicamente enmarcadas en la regulación que hoy analizamos que vulneran regulaciones sustantivas de la misma, pero que no tienen cabida, como ya he indicado, en la Ley 14/1986. En definitiva, la disposición analizada manifiesta una huida de la regulación del régimen sancionador y con ello se deja la ley inacabada y coja, señorías, abriendo una puerta ancha a la ineficacia y abocando a la Administración para evitar dicha ineficacia, a caminar por la nebulosa senda de lo permitido y prohibido en la interpretación del régimen sancionador de la Ley de 1986 y habrá ocasiones en que por falta de tipicidad se incurra en inconstitucionalidad. Señorías, nada es tan frustrante - lo digo desde la experiencia de haber sido responsable en la Administración de la Comunidad Autónoma del País Vasco- como que una norma sancionadora esté mal hecha y que una ley magnífica resulte, en definitiva, ineficaz porque sea imposible aparejar a su incumplimiento determinadas respuestas».

Quizás para evitar estos peligros, y teniendo presentes las previsiones efectuadas por las respectivas leyes de salud autonómicas y los artículos 
32-37 de la Ley General de Sanidad, se recogen las infracciones y sanciones que se pueden imponer a este tipo de establecimientos ${ }^{88}$ con carácter específico. Las competencias sancionadoras se determinarán reglamentariamente, correspondiendo la facultad de incoar e instruir los procedimientos, al órgano municipal competente ${ }^{89}$, aunque la Administración autonómica pueda actuar en sustitución de los Municipios, en los supuestos y con los requisitos previstos en la legislación de régimen local. Todo ello sin perjuicio de las responsabilidades civiles, penales o de otro orden que, en su caso, pudieran concurrir.

\section{Medidas cautelares}

El órgano municipal competente mediante acuerdo motivado y previa audiencia al interesado, puede adoptar las medidas provisionales que resulten necesarias y cerrar, si procede cautelarmente, las instalaciones que no cuenten con la autorización determinada reglamentariamente. En el supuesto de que se constate un incumplimiento de las condiciones sanitarias establecidas, y hasta que no se resuelvan los defectos detectados o se cumplan los requisitos previstos, podrá suspender temporalmente el funcionamiento del establecimiento o la prestación de estos servicios.

La adopción de estas medidas no tiene carácter de sanción ${ }^{90}$. La Ley General de Sanidad, art. 37, determina que no tendrán carácter de sanción, la clausura o cierre de establecimientos, instalaciones o servicios que no cuenten con las previas autorizaciones ${ }^{91} \mathrm{o}$ registros sanitarios preceptivos, $\mathrm{o}$

${ }^{88}$ Vide Decreto 286/2002, de 26 de noviembre, de la Consejería de Salud de la Junta de Andalucía, art. 16; Decreto 160/2002, de 30 de abril, del Departamento de Salud, Consumo y Servicios Sociales de Aragón, arts. 10 y 11; Orden 17/2003, de 14 de marzo, de la Consejería de Sanidad y Consumo de Murcia, arts. 10.3, 11.1 y 11.2; Decreto 28/2001, de 23 de enero, del Departamento de Sanidad y Seguridad Social de la Generalitat de Catalunya, art. 17; Decreto Foral 132/2002, de 17 de junio, art. 10, que remite al Capítulo VII del Título II de la Ley Foral 10/1990, de Salud, que a su vez remite a la LGS;

${ }^{99}$ Vide Decreto 286/2002, de 26 de noviembre, de la Consejería de Salud de la Junta de Andalucía, art. 18; Decreto 160/2002, de 30 de abril, del Departamento de Salud, Consumo y Servicios Sociales de Aragón, art. 12; Decreto 28/2001, de 23 de enero, del Departamento de Sanidad y Seguridad Social de la Generalitat de Catalunya, art. 19.

${ }^{90}$ Vide Decreto 286/2002, de 26 de noviembre, de la Consejería de Salud de la Junta de Andalucía, art. 17; Decreto 160/2002, de 26 de noviembre, del Departamento de Salud, Consumo y Servicios Sociales de Aragón, art. 13; Decreto 28/2001, de 23 de enero, del Departamento de Sanidad y Seguridad Social de la Generalitat de Catalunya, art. 18.

${ }^{91}$ Vide STS de 25 de abril de 1991 (Ar. 3083): «[...] en el Reglamento como en otras reglamentaciones administrativas, coexisten dos órdenes de reglas o medidas en manos de la Administración con potestad interventora en el sector regulado por aquéllas, siquiera a veces no aparezcan en las 
la suspensión de su funcionamiento hasta tanto se subsanen los defectos o se cumplan los requisitos exigidos por razones de sanidad, higiene o seguridad 92. Así ha sido recogido en la legislación autonómica dictada al efecto:

«La clausura o cierre de centros, servicios, establecimientos o instalaciones que no cuenten con las autorizaciones o registros sanitarios preceptivos, la suspensión de su funcionamiento hasta tanto se rectifiquen los defectos o se cumplan los requisitos exigidos por razones de sanidad, higiene o seguridad, así como la retirada del mercado precautoria o definitiva, de productos o servicios por las mismas razones, se acordará por la autoridad sanitaria competente, no teniendo estas medidas carácter de sanción» ${ }^{93}$.

En el caso de un procedimiento sancionador, y una vez iniciado, el órgano competente para resolver podrá adoptar, mediante acuerdo motivado, las medidas provisionales que resulten necesarias para asegurar el cumplimiento de la resolución que pudiera recaer y, en todo caso, asegurar el cumplimiento de la legalidad y salvaguarda de la salud pública. Entre otras se contemplan las siguientes: a) La suspensión total o parcial de la actividad; b) La clausura de centros, servicios, establecimientos o instalaciones; c) La exigencia de fianza ${ }^{94}$.

normas reglamentarias suficientemente deslindadas, cuales son a) las sanciones propiamente tales de signo pecuniario (multas) o de otro contenido restrictivo de derechos o intereses de los administrados, dirigidas a reprochar los ilícitos administrativos que aquellas normas tipifican con la adecuada cobertura legal; y b) las medidas de policía que no son sanciones, encaminadas a la vigilancia sobre las necesarias y previas autorizaciones administrativas, que pueden desembocar, si no existen aquéllas o se han quebrantado las condiciones impuestas en las mismas al cierre de los locales, dirigido a impedir el funcionamiento de una actividad surgida sin la autorización previa y preceptiva o contraviniendo alguna forma».

92 Vide Ignacio Pemán Gavín, «Dificultades para una delimitación sustantiva del concepto de sanción. Pautas para un replanteamiento de la cuestión», Revista Aragonesa de Administración Pública, 14, (1999), pp. 201 y 202, donde se pronuncia sobre la naturaleza jurídica de estas medidas.

${ }_{93}$ Vide Ley 2/1998, de 15 de junio, de Salud de Andalucía (art. 29); Ley 6/2001, de 15 de abril, de Salud de Aragón (art. 44); Ley 11/1994, de 26 de julio, de Ordenación sanitaria de Canarias (art. 41); Decreto 65/1992, de 7 de septiembre, de Cantabria, por el que se regula la autorización de centros, servicios y establecimientos sanitarios (art. 8); Ley 1/1993, de 6 de abril, de Ordenación del Sistema Sanitario de Castilla y León (art. 18.3); Ley 10/2001, de 28 de junio, de Extremadura, normas reguladoras de la salud (art. 56); Ley 4/1989, de 26 de julio, de Murcia, normas reguladoras de sanidad [(art. 11). Vide Decreto 22/1991, de 9 de mayo, sobre autorización de centros, servicios y establecimientos sanitarios, art. 8: «Corresponderá a la Consejería de Sanidad, sin perjuicio de la legislación básica del Estado, establecer y exigir los requisitos técnicos y las condiciones que, exclusivamente por razones de sanidad, higiene o seguridad, deban reunir las instalaciones y establecimientos sanitarios»]; Ley Foral 10/1990, de 23 de noviembre, de Navarra, normas reguladoras de salud (art. 31); Ley 2/2002, de 17 de abril, de Salud de La Rioja [(art. 114.1). Vide Decreto 5/1992, de 6 de febrero, de registro, catalogación e inspección de centros, servicios y establecimientos sanitarios (art. 17.2)]; Decreto 396/1994, de 11 de octubre, del País Vasco, por el que se regula la apertura, funcionamiento y modificación de centros, servicios y establecimientos sanitarios (art. 13).

${ }^{94}$ Vide Ley 2/1998, de 15 de junio, de Salud de Andalucía (art. 28); Ley 6/2001, de 15 de abril, de Salud de Aragón (art. 43); Ley 5/2003, de 4 de abril, de Salud de las Islas Baleares (art. 59.2); Ley 


\section{Revocación de la autorización}

Cuando la Administración vuelve sobre sus propios actos al margen de si son o no conformes a Derecho, no para verificar su legalidad, sino la conveniencia de su mantenimiento por razones de interés público, estamos ante la revocación en sentido estricto ${ }^{95}$. La Administración decidirá entonces acerca de la privación de efectos del acto, abstracción hecha de si es o no válido. Por tanto, la revocación en sentido estricto es el acto de contrario imperio de la Administración autora, encaminado al expurgo del mundo jurídico de un acto administrativo por motivos de oportunidad.

La revocación de las autorizaciones administrativas será acordada por el órgano que las concedió, previo expediente instruido al efecto con audiencia del interesado. Técnicamente estaríamos ante un supuesto de revisión de actos administrativos por las Administraciones públicas, que no tiende propiamente a verificar la conformidad con el Ordenamiento jurídico. Aun cuando la revocación puede darse a instancia de persona distinta a la autora del acto, normalmente se producirá de oficio como consecuencia de un acta de inspección ${ }^{96}$.

\section{CONCLUSIÓN}

Para poner punto final a esta colaboración debo pronunciarme sobre las consideraciones que expuse al principio. Quizás ahora esté mejor pertrechado para afirmar que la aplicación de normas sanitarias a establecimientos no sanitarios deriva del propio bien jurídico a proteger. El ser humano. Pero dicho esto, debo manifestar que va a resultar difícil que empresas y profesionales se adapten y cumplan todas las exigencias que han sido expuestas, que no son pocas. Máxime, cuando se trata de una

8/2000, de 30 de noviembre, de Ordenación de la Sanidad de Castilla-La Mancha (art. 42); Ley 10/2001, de 28 de junio, de Extremadura, normas reguladoras de la salud (art. 55); Ley Foral 10/1990, de 23 de noviembre, de Navarra, normas reguladoras de salud (art. 30); Ley 2/2002, de 17 de abril, de Salud de La Rioja (art. 113).

95 Vide Orden de 29 de marzo de 2001, de Galicia (DOG de 11 de abril, núm. 72; corrección de errores $D O G$ de 23 de mayo, núm. 98), art. 12: «Revocación de la autorización de funcionamiento. La autorización de funcionamiento se entenderá revocada si en el plazo de tres meses, computados desde la notificación de la citada autorización, no se iniciase la actividad o permaneciese interrumpida más de seis meses una vez iniciada. También se entenderá revocada si se procede al cierre del centro, servicio o establecimiento sanitario, se alterasen sustancialmente las condiciones originarias que sirvieron de base para su otorgamiento, se trasladasen sus instalaciones a otro lugar de la misma o distinta localidad o no se hubiese solicitado la correspondiente renovación».

${ }^{96}$ Vide Orden 17/2003, de 14 de marzo, de la Consejería de Sanidad y Consumo de Murcia, art. 9.8 . 
actividad que navega entre lo comercial y el culto a una determinada imagen ${ }^{97}$.

Por otra parte, su catalogación como establecimientos no sanitarios genera una duda razonable más allá de la realidad cotidiana. No es de extrañar que haya normas que determinan que quedan excluidos de la regulación que contienen, por no tener naturaleza de establecimientos sanitarios, $y$, en consecuencia no exigirse la presencia de un responsable sanitario, aquellos establecimientos dedicados a practicar masajes no terapéuticos y los dedicados a cosmética y estética, siempre que en ellos no se realicen tratamientos médicos ni se apliquen procedimientos percutáneos, electromecánicos, radiaciones físicas o similares, en cuyo caso, serán considerados centros sanitarios a todos los efectos quedando sujetos a lo establecido en la legislación autonómica dictada al efecto ${ }^{98}$.

Respecto al régimen competencial expuesto, y dada la dificultad que existe en la práctica para la coordinación entre Administraciones públicas y las disociaciones que establece la normativa, considero que ejercerían un mejor control las autoridades sanitarias de las Comunidades Autónomas que añadirían este tipo de centros al elenco de los enumerados en las disposiciones que regulan la autorización y registro de centros y establecimientos con carácter general.

\footnotetext{
${ }^{97}$ Vide Sentencia de la Audiencia Provincial de Murcia 59/2002 (Sección 2. a), de 15 de abril, Jurisdicción Penal, originada por que su sujeto le dice a otro «que el tatuaje que llevaba en el brazo izquierdo no le pegaba y que le iría mejor una flor de lis en el pecho».

${ }^{98}$ Vide Decreto 163/1996, de 26 de julio, de Baleares, que regula la autorización para la creación, modificación, traslado y cierre de centros, establecimientos y servicios sanitarios (BOIB de 17 de agosto, núm. 103), art. 2.2.c).
} 